\title{
Beyond Affective Congruence
}

\author{
Alexander Joseph Schiller \\ Lynden, Washington \\ Bachelor of Arts, Western Washington University, 2010 \\ Master of Arts, University of Virginia, 2013 \\ A Dissertation Presented to the Graduate Faculty \\ of the University Of Virginia in Candidacy for the Degree of \\ Doctor of Philosophy
}

\section{Department of Psychology \\ University of Virginia}

August, 2017 


\begin{abstract}
Emotions and moods are affective states that sometimes influence evaluative judgments. The most common research finding is that affect colors evaluations to be affect congruent. For example, people in positive affective states generally make more positive evaluations than people in negative states. The literature on affect and judgment is so consistent that one might assume that the influence of affect on judgment is always affect congruent, so that people in positive affective states evaluate everything more positively. This dissertation, however, asks what happens when a person in a positive state is confronted with a negative judgment object. Do people in happy moods see lying, cheating, or stealing as less bad than they otherwise would? Despite the consistency in the literature on affective congruence, I propose that affect often does not lead to affect-congruent evaluation, but rather that the direction of affective influences on evaluations often depends on participants' initial opinion of the target of evaluation. In this dissertation I will explore situations that do not lead to congruence, but instead lead to affective incongruence (Study 1), to influences on the extremity of responses (Study 2), and to affective enhancement of existing beliefs (Studies 3 and 4). In a final study, I tested the effect of mood on experimentally manipulated positive and negative targets. The goal of the dissertation is to examine the judgment conditions under which affect incongruence, rather than affect congruence, may occur and to propose an explanation to account for both traditional and new patterns of results.
\end{abstract}

Keywords: affective congruence, emotion, mood, judgment, evaluation 


\author{
In memory of my father \\ Jeff Schiller \\ January 14, 1960 - November 25, 2016 \\ "The best preparation for tomorrow is doing your best today." \\ - H. Jackson Brown, Jr.
}




\section{Acknowledgments}

My father sent out a daily "Thought for the day" email that included motivational quotes, stories, and his own personal writing. The quote above came from his final TFTD. I can thank no one more than my father for who I am today.

I also want to thank Jerry for all of his time over the years. Our meetings are the thing I will miss most when I finally leave Charlottesville. More thanks to the rest of my committee, Tim, Ben, and Eileen, for taking the time to think about and discuss my work.

Another set of thanks to my brothers (Eric and Addison), mom, step-mom, and the rest of my family for all of their encouragement over the years. To Andy whose near daily badgering (“Did you finish your thesis?") motivated me more than I care to admit. Finally, no acknowledgments section would be complete without thanks to my wife, Allison. 
All living things must constantly evaluate their surroundings in order to make choices. Today, more than ever before, the opinions and evaluations that people make publicly have an impact. Every restaurant review on Yelp, product review on Amazon, or movie review on IMDB can influence how other people choose to spend their money. A string of poor reviews can sink a business, leave a product sitting in a warehouse, or turn a movie into a financial failure. While the quality of reviews may generally reflect the quality of products, incidental factors can also influence the favorability of evaluations. One such factor is the affective state of the individual at the time of judgment.

Over the last 40 years, incidental positive and negative affective states have been found to be important influences on judgments and evaluations. The importance of affect in evaluation has been observed in a variety of fields, including law (e.g., Blumenthal, 2005), business (e.g., Brief, Butcher, \& Roberson, 1995; Bakamitsos \& Siomkos, 2004), and healthcare (e.g., Pettit, Kline, Gencoz, Gencoz, \& Joiner, 2001). With over 100 million reviews on Yelp (Yelp, March, 2016), it is credible that even small differences in affect might lead to important differences in review accuracy and reliability. The importance of the current research is not limited, however, to documenting possible affective biases in evaluative judgment. Studies of how target-irrelevant affect influences judgment also allow a test of larger theoretical ideas about how affect influences evaluative judgment, whether the affect is relevant or irrelevant to the judgment. It is important to ask, therefore, how does affect influence evaluation?

\section{What is affective congruence?}

One of the most common findings in research on affective states is that people make affect-congruent evaluations (Bagozzi, Gopinath, \& Nyer, 1999). The basic finding is that people 
in positive affective states rate objects (persons, places, things, or ideas) more positively than people in negative states. In one example, Isen and colleagues demonstrated the affect-congruence phenomenon by giving participants a small gift and then asking them to evaluate an unrelated product (Isen, Shalker, Clark, \& Karp, 1978). Participants who received a gift evaluated their mood and the unrelated product more favorably than those who did not receive a gift. Isen et al.'s study showed that a source of positive affect unrelated to the object being evaluated could shift evaluations in an affect-congruent way. In another example, Schwarz and Clore (1983) asked people to complete life satisfaction surveys on days with particularly pleasant or unpleasant weather. They found that better weather enhanced mood, which in turn led to higher ratings of life satisfaction. Similar effects have been found in a variety of domains ranging from evaluation of advertisements (Srull, 1983) to impressions of others (Forgas and Bower, 1987; Gouaux, 1971; Griffitt and Veitch, 1971). In each of these cases, positive affective states led to more positive evaluations and negative affective states to more negative evaluations.

\section{Components of the affect-congruence phenomenon}

Two things are required to elicit the affect-congruence phenomenon: an evaluative judgment and affect. Studies showing the phenomenon generally involve an evaluative scale that has a positive and negative pole, such as a scale of liking ranging from like very much to dislike very much, or a scale of life satisfaction with options ranging from extremely satisfied to extremely dissatisfied (e.g., Schwarz \& Clore, 1983). The nature of the scale does not seem to matter so long as there is an evaluative component. Thus, given some evaluative tone, judgments should tend to elicit the affect-congruence phenomenon. 
The second component required for affect congruence is affect. While most of the work on the affect-congruence phenomenon has relied on induced mood states, there are a variety of sources of affect that can influence behavior. Moods and emotions are two of the most common kinds of affective states. Emotions differ from moods in that emotions are about a specific object (e.g., situation, thought, person), whereas moods tend to be nonspecific in their objects (Clore \& Colcombe, 2003). Research on affect congruence typically employs induced mood states as a ready source of affect. A wide variety of methods have been used to induce positive and negative affect (review: Coan \& Allen, 2007). For example, Griffitt and Veitch (1971) had participants work in an overcrowded room on a hot day to induce negative affect. Another early study used happy or sad films to induce positive or negative moods (Gouaux, 1971). The goal in these early studies was to induce an affective state with content that did not overlap with substantive aspects of the target of evaluation. The purpose was to determine the influence of affect independently of the influences of relevant cognitions and beliefs about the target. Many studies now utilize film to induce affective states, often using clips from movies such as Sophie's Choice (sadness) or James Bond (happiness; e.g., Storbeck \& Clore, 2011). Other researchers have induced affective states by giving small gifts to participants (e.g., Isen et al., 1978), having participants read positive and negative stories (e.g., Huntsinger, Clore, \& Bar-Anan, 2010), or administering either a positively or negatively focused writing task (e.g., Gasper \& Clore, 2002). All induction methods covered so far involve conscious affect, but nonconscious affect can also have an influence. Zajonc and colleagues found more positive ratings after subliminally-presented happy faces than after subliminal angry faces (Murphy \& Zajonc, 1993; Winkielman, Zajonc, \& Schwarz, 1997). While the experimental manipulation of affect has advantages, it is not the only 
way to study affect. Researchers also measure naturally-occurring moods (Gasper \& Clore, 2002), moods resulting from weather changes (Schwarz \& Clore, 1983), or trait levels of affect as indicated by personality measures such as extraversion, which are primarily measures of positive affect (Tamir, Robinson, \& Clore, 2002). Given the wide range of methods that have been used, the particular source of affect does not appear to matter. Indeed, Zhang, Yu, and Barrett (2014) assessed the effectiveness of a number of inductions and found them all to be relatively effective at inducing the desired state. Any affect, regardless of the source, may be sufficient to exert an influence on judgment, thought, or behavior.

\section{Memory hypothesis}

One commonly encountered explanation of affect congruence assumes that the evaluations people make reflect material retrieved from memory. Specifically, the memory hypothesis is that affective states activate affect-congruent material in memory. This hypothesis draws on Semantic Associative Memory theory (Anderson \& Bower, 1973), which postulates a semantic network of nodes in which each node represents a relevant concept. When one concept is activated, other nodes in the network will also become activated. The phenomenon of semantic priming provides an example of the process. For example, after hearing the word "nurse," people are faster to identify the word "doctor" than without having been primed with "nurse." The idea is that when "nurse" is encountered, terms associated with that concept (e.g., "doctor," "hospital," "sick") also receive activation and are therefore more readily recognized. This spreading activation model was applied to affect by hypothesizing that just as words activate associated words, affective states activate affect-congruent thoughts. Such affect-congruent 
material is then especially accessible, leading to more positive evaluations in positive moods and more negative evaluations in negative moods.

Alice Isen and Gordon Bower simultaneously, but independently, proposed virtually the same model of how semantic associations in memory could explain affect congruence (Bower, Monteiro, \& Gilligan, 1978; Isen et al. 1978). Does being in a mood make mood-congruent thoughts and memories more likely? Study 2 in Isen et al. (1978) showed that people who were randomly selected to win rather than lose a computer game were subsequently better able to recall a list of positive words. They suggested that the link between positive mood and evaluation could be explained by an increase in the accessibility of positive thoughts about the target of evaluation. Teasdale and Fogarty (1979) further demonstrated that people were faster to recall memories that matched their current affective state, supporting the hypothesis that mood might influence the accessibility of mood-congruent memories. In another line of work, Parrott and Sabini (1990) had people recall memories while listening to positive or negative music. Interestingly, mood-congruent memory occurred only when participants were told how the music was intended to make them feel. The findings of Parrot and Sabini (1990) make it plausible that many of these memory effects are due to conceptual priming rather than to the experience of mood. In other words, telling people what the music was supposed to make them feel provided concepts capable of priming memories. Similarly, other modes of mood induction (e.g., hypnosis) also run the risk of producing mood-congruent memories via conceptual priming rather than by mood (Gilligan \& Bower, 1983). One explanation that was proposed for mood-congruent memory involved the phenomenon of state dependent learning (Bower, 1981). For example, it is likely that happy memories were acquired originally when the person felt 
happy, and later recall might be enhanced by reinstating that happy mood. Bower had originally demonstrated mood congruence in the recall of word lists, free associations, and in recollections of affectively charged diary entries (Bower, 1981). However, later research failed to replicate such state dependent memory effects for mood (Bower \& Mayer, 1985). Additional concerns came from the social cognition literature. If positive mood activates positive memories and leads to positive judgments, memories and judgments should be highly related. However, Wyer and Srull (1989) reviewed the literature and found little relationship between impressions of people and recollections of their actual behavior. These findings are inconsistent with the hypothesis that mood effects on evaluation are mediated by mood-congruent memories.

\section{Affect-as-information hypothesis}

A second commonly encountered explanation of the affect-congruence phenomenon is the affect-as-information hypothesis (Schwarz \& Clore, 1983; 2007). The affect-as-information approach maintains that one function of affect is to serve as embodied information about value. Affect then provides a potentially persuasive source of information on which to make evaluations. From that perspective, affective influences are not due to affect alone, but to affect that is implicitly attributed to a target of evaluation. Ordinarily, the affect elicited by targets of evaluation is then reflected in whatever evaluative judgment follows. However, the critical role of attributions in connecting affect and objects opens the possibility that affect can be misattributed to substitute objects under certain conditions (Clore et al., 2001). Thus, in studies of mood and judgment, the affect is typically due to an irrelevant mood state, requiring appropriate experimental timing and subtlety to foster misattribution of the affect from mood to the object of judgment (e.g., Schwarz \& Clore 1983). How and when affect is used as 
information in this way can be explained through a few guiding principles (Clore, et al., 2001). The first principle is the Affective Judgment Principle, which says that when people focus on an object, the affect from mood can serve as positive or negative information about that object (where "object" can also refer to persons, events, ideas, and so on).

The second principle is the Affect Immediacy Principle, which says that affect is always about whatever is in mind at the time. People continually assess the state of the world in order to make decisions and to act. Information from the world is processed and used to guide decisions and actions. In this process, information about aspects of objects such as their color, shape, and weight may be perceived automatically and accurately. When holding a heavy object in one's hand, there is no question about the source of the experience of heaviness. By contrast, the source of an experience of affect is sometimes less clear. Indeed, people often do not know why they feel the way they do (Wilson, 2002). When making decisions or evaluating a situation, they implicitly ask themselves how they feel about something (Schwarz \& Clore, 1988). At that point, their current feeling is likely to be experienced as part of the answer to that question. Unlike the experience of heaviness, which is closely tied to an object, the more loosely-anchored experience of affect may be misattributed as a reaction to something other than its original source. In particular, the Affect Immediacy Principle says that affect is likely to be experienced as information about whatever is currently in mind. During evaluative judgment, of course, what is in mind is likely to be the target of evaluation.

A third guiding principle is the Attribution Principle, which says that the influence of affect depends on that to which affect is attributed (Clore et al., 2001). Affective influences, therefore, depend not on the affect itself but on the information conveyed by the affect, which 
depends on its apparent source, that is, the object to which it is attributed. Affect carries information about value, but as we see next, its impact depends on which object appears to have such value. The affect as information hypothesis holds that affective feelings convey information that serves as input to judgment, thought, and action. When affect congruence occurs, affective feelings serve as a direct source of information such that positive affect leads to positive evaluations, and negative affect to negative evaluations.

\section{When do affective influences operate?}

The influence of affect on behavior can sometimes be erased. That conclusion comes from an early study by Schwarz and Clore (1983) that manipulated people's attributions for their affective feelings. Affective attribution refers to the identification of the source of affect or what the affect is about. Often, affective reactions are focused on something specific, such as fear in response to a snake, such that the appropriate attribution is quite clear. Nevertheless, however fixed and obvious the object may be, fear must still be attributed as a reaction to the snake for it to influence thought and action appropriately. Such attributions are generally automatic and unconscious, but in laboratory studies of mood, experimenters sometimes alter people's attributions by directing their attention to a particular possible cause. For example, some participants in Schwarz and Clore's (1983) experiment were asked about the current weather prior to making life-satisfaction judgments. By attributing their current affect to the weather, it was not experienced as information about life satisfaction in the way it was for participants asked immediately about life satisfaction. Making an attribution does not mean that the affective state disappears. Instead, attributions simply limit the range of things likely to be influenced by affect. 
Thus, for example, knowing why one is embarrassed clarifies the meaning of the embarrassed feelings but does not diminish it.

A second condition governing whether affect has an influence on behavior concerns whether or not substantive processing is required (Forgas, 1995). If a target of evaluation is well known or has been previously evaluated, judgments may require little or no substantive processing. One demonstration of this principle is that the evaluations by novices are more likely to be influenced by affect than those by experts (Srull, 1983). Compared to those of experts, evaluations by novices require more extensive processing. Importantly, this relative immunity of experts to affective influence was found to vanish when the experts evaluated targets outside of their expertise. The experts acted like novices who, because they lacked relevant experience to draw upon, had to engage in information processing that could be influenced by affect. In a similar manner, judgments of previously evaluated targets also do not show an influence of affect (Salovey \& Birnbaum, 1989). Instead of reprocessing the information, people may rely on any previous evaluations they have made to make rapid judgments uninfluenced by affect. Thus, in the current view, the process of thinking increases the likelihood of affect playing a role in evaluation rather than immunizing against affective influence as traditional views assume (Greifeneder, Bless, \& Pham, 2011).

\section{Beyond affective congruence}

The affect-congruence phenomenon appears to be a reliable effect that occurs when a person experiencing some form of affect makes an evaluative judgment (e.g., Isen et al. 1978; Schwarz \& Clore, 1983; Srull, 1983). The source of the affect and the type of evaluation being made do not appear to matter. The two primary hypotheses used to explain the affect-congruence 
phenomenon focus on affect (either through memory or misattribution) changing the value of the target of evaluation. Both the memory hypothesis and the affect-as-information hypothesis are used to explain when the affect-congruence phenomenon will occur and when it will not occur. Neither hypothesis makes predictions about other patterns of results that affect could lead to. For example, according to the memory hypothesis, mood should not influence evaluation if there are no associations that match the valence of the current mood (Isen, 2008). There must be a match between the valence of the associations to be activated and the valence of the affect for mood effects to occur. According to Isen (2008, p. 551), participants “... would not be expected to rate mildly negative material as more negative, as if just judging everything as more extreme."

\section{Extremity effects}

In contrast to the prediction made by Isen (2008) that positive affect should not simply make ratings more extreme, two studies have found evidence of just such extremity effects (Schiller, 2014). In one experiment, participants induced to be happy or sad were asked to evaluate a Lance Armstrong LIVESTRONG bracelet shortly after Armstrong was revealed to have used performance enhancing drugs to achieve his Tour de France wins. Counter to the affect-congruence phenomenon, happy participants evaluated the LIVESTRONG bracelet more negatively than sad participants.

In a second study, Schiller (2014) conducted a conceptual replication of Schwarz and Clore (1983) in which participants induced to feel happy or sad were asked to evaluate their life satisfaction. Consistent with the affect-congruence phenomenon, participants in happy moods evaluated their lives more positively than those in sad moods. However, an analysis of the extremity of responses (distance from the midpoint on the scale) revealed that happy people were 
also more extreme in their responses, an effect that accounted for somewhat more variance than the standard unidirectional effect. In other words, evaluations in positive moods were both more positive and more negative rather than simply more positive, as is usually observed.

While the life-satisfaction study showed evidence of affect congruence, both the life satisfaction and the Lance Armstrong studies showed evidence of something different (Schiller, 2014). One possible explanation is that positive affect enhances or reinforces current beliefs or thought. For the LIVESTRONG bracelet, positive affect might add value to negative thoughts about the bracelet, enhancing a pre-existing negative view of Armstrong. The extremity effect in the life-satisfaction experiment is trickier. Most people are generally happy with their lives (Biswas-Diener, Vittersø, \& Diener, 2005). Despite this fact, not everyone is satisfied. Hence, positive affect could reinforce the positive life satisfaction of most people as well as the dissatisfaction of others, resulting in more extreme judgments. Neither the memory hypothesis nor the standard affect-as-information hypothesis make predictions consistent with these results.

\section{Evidence for affect as reinforcement}

One line of related work is on affect and persuasion. In their research, Briñol, Petty and colleagues have shown that affect can play a role in persuasion by modifying the confidence people have in their own thoughts (Petty \& Briñol, 2015; Briñol, Petty, Gallardo, \& DeMarree, 2007). As in the present thesis, Briñol and Petty also propose that affect may take as its object not what is being judged but one's thoughts about that thing. For example, they gave participants either strong or weak arguments about a topic and then asked them to evaluate a proposal. In one study, participants were given strong or weak arguments in favor of implementing comprehensive student exams for college seniors before undergoing a positive or negative mood 
induction (Briñol, Petty, \& Barden, 2007). When asked to evaluate the quality of the strong arguments, happy participants were more in favor of the proposal than sad participants. However, when evaluating the weak arguments, sad participants rated the proposal more favorably. According to Briñol and colleagues, participants given strong arguments generated more favorable thoughts about the proposal. Then, positive affect from the happy mood induction reinforced the strength of the arguments, and negative affect from the sad mood induction weakened the strength of the strong arguments. When evaluating the weak arguments, the unfavorable thoughts were reinforced by positive affect which led to the most negative evaluations of the proposal. In sad moods, however, the value of the weak thoughts were diminished, leading to more moderate evaluations. The heart of the argument is that affect modifies thought confidence, which in turn influences persuasion.

Briñol and Petty thus offer a different take on a similar idea. Their work focuses heavily on how affect plays a role in changing the value of strong and weak arguments through thought confidence. It is difficult to apply affect-congruence theories to Briñol and Petty's work because persuasive arguments do not have inherent polar values (i.e., side A is positive and side B is negative). However, the affect-reinforcement view is not at odds with the work on persuasion. While Briñol and Petty focus on the role of thought confidence instead of direct modifications to value, both views come to similar conclusions: affect can serve to validate or invalidate thoughts.

\section{Rethinking affective congruence}

In this dissertation, I present evidence of three patterns of results that are inconsistent with the affect-congruence phenomenon: affect-incongruent (Study 1), extremity (Study 2), and belief-enhancement (Studies 3 and 4) effects. "Affect-incongruent" effects are those in which 
participants experiencing positive affect evaluate something more negatively than sad participants. The Lance Armstrong study in Schiller (2014) is an example of an affect-incongruent effect. "Extremity" effects are those in which ratings by participants experiencing positive affect are more extreme on the scale than those experiencing negative affect. The life-satisfaction study in Schiller (2014) is an example of evidence for extremity of response. Finally, "belief-enhancement" effects are instances in which participants experiencing positive affect are more positive toward a position they are predicted to hold from a knowledge of associated beliefs. While there is already sufficient evidence to believe that the affect-congruence phenomenon occurs, the initial evidence from Schiller (2014) suggests that other influences of affect on evaluation have yet to be fully explored. These three new patterns of results represent an opportunity to better understand the affect and judgment phenomenon and to clarify the processes through which affect influences evaluation. Later in the dissertation, I propose a single explanation for these three patterns.

The goal of this dissertation is to show that affect congruence is not the only way that affect can influence evaluation. The initial findings of affect incongruence represents the emergence of a new phenomenon. Accordingly, I completed 5 studies to replicate and extend this initial research. Data have been collected and analyzed for the replication study (Study 1). In addition, data from three existing (big data) sources have been analyzed to further examine the phenomena of interest in naturally-occurring judgments (Studies 2, 3, and 4). In a final study, mood was induced and the valence of the description of a person was manipulated to examine when evaluations show affect congruency and incongruency (Study 5).

\section{Study 1}


Initial studies finding evidence for affective incongruence focused on ratings of life satisfaction and on liking for Lance Armstrong LIVESTRONG bracelets (Schiller, 2014). One major question raised throughout this work was the reproducibility of the main finding. The main effect was that people in positive moods reported liking the LIVESTRONG bracelet less than did those in sad moods. The study was conducted shortly after it had been confirmed that Lance Armstrong's cycling success was aided by doping. Study 1 of the dissertation was undertaken to determine whether this effect was replicable. Participants were asked to rate their liking for a poster of Alex Rodriguez shortly after it was confirmed that his performance also was aided by the use of steroids. If the initial effect (Schiller, 2014) holds up, happy moods should result in lower levels of liking for a poster of Alex Rodriguez than do sad moods, because Rodriguez, like Armstrong, was expected to be generally negatively evaluated.

\section{Method}

Participants. Participants were recruited for payment on Amazon's Mechanical Turk. A total of 105 individuals participated. Sixteen participants were then excluded for writing for fewer than 70 seconds or writing fewer than 20 words during the mood induction procedure, which involved describing a happy or sad event. The same criteria were employed as in previous research (Schiller, 2014). Those who were unfamiliar with Alex Rodriguez were also excluded $(N=19)$. The final sample included 70 participants (Happy group $=31$, Sad group $=39 ;$ women $\left.=28 ; M_{\text {age }}=32.04, S D_{\text {age }}=12.21\right)$.

Procedure. Participants initially read a paragraph about Alex Rodriguez and the scandal surrounding his steroid use (Appendix A). They were then asked to write for approximately two minutes about a recent positive or negative life event (Writing time in seconds, $M=173.77, S D$ 
$=125.19$; Word count, $M=83.89, S D=44.88$ ). After this mood induction, they rated their liking for an Alex Rodriguez poster. Altogether, they rated four products, the first of which was the critical item (the poster of Alex Rodriguez) and the other three served as filler items. Four ratings were collected, two of which served as the liking variable of interest ("How much do you like this product?", "How much do you think the average person would like this product?"). Ten-point response scales were used (1 - Not at all, 10 -). Participants then gave demographic information, answered a few questions about the mood induction, and were debriefed.

\section{Results}

Mood Manipulation Check. Two items assessed the mood of the participants: "How happy did you feel while writing?" and "How sad did you feel while writing?" Individuals in the happy group reported feeling happier than those in the $\operatorname{sad} \operatorname{group}(M s=3.94,1.87, S D s=1.15$, 1.17), $t(69)=7.36, p<.001$, and those in the sad group reported feeling more $\operatorname{sad}(M s=3.49$, $1.29, S D s=1.31, .59), t(68)=8.63, p<.001$.

Product Ratings. The two liking questions were merged into a single scale (Cronbach's $=.84)$. As predicted, participants in the happy group rated the Alex Rodriguez poster more negatively than did those in the sad group $(M s=8.61,11.10, S D s=3.77,4.13), t(68)=2.60, p=$ $.011, R^{2}=.09$.

\section{Discussion}

Consistent with the results of Schiller (2014), in the present study, ratings of the Alex Rodriguez poster were more negative when people were happy than when they were sad. These results are contradictory to what would generally be expected given the consistency of the data showing affect congruence. Neither the memory hypothesis nor the usual version of the 
affect-as-information hypothesis lead to expectations of affect incongruence. Why might affect be leading to incongruent evaluation? The memory explanation for affective influences (Forgas $\&$ Bower, 1987; Isen, 1984) assumes that affect makes affect-congruent information more accessible. The affect-as-information hypothesis makes similar predictions by assuming that affect adds value to the object of evaluation. Neither leads one to expect affect incongruence, because they generally assume that affect changes perceptions of the target of evaluation directly. An alternative possibility is that affect serves not directly as information about the target of evaluation, but as information about the value of one's thoughts, and hence only indirectly as information about the object of evaluation. Positive affect should reinforce such thoughts, and if judges' initial thoughts about the target of evaluation are unfavorable, then positive affect should lead to especially unfavorable ratings of the target.

The difference between the Alex Rodriguez and Lance Armstrong studies and studies showing the affect-congruence phenomenon lies in the likely valence of targets of evaluation. In most situations where affect congruence has been reported, the target of evaluation seems likely to have been initially positive. For example, Isen et. al (1978) obtained ratings of people's household appliances, such as their refrigerators, and Schwarz and Clore (1983) obtained ratings of life satisfaction. In contrast, Alex Rodriguez and Lance Armstrong were chosen as targets because participants were likely to have negative associations with them at the times when these two studies were conducted. If affect served as feedback about those thoughts instead of directly as information about Rodriguez and Armstrong, then positive affect might reinforce those initial negative views leading to affect incongruent judgment. This view is also consistent with Briñol and Petty's persuasion work (Petty \& Briñol, 2015), but might be phrased better as positive 
affect increasing confidence in the negative thoughts. In any case, the results of the current Study 1 replicated, with Alex Rodriguez as the target, the interesting reversal of the standard affect-congruent evaluation found previously with Lance Armstrong as the target.

Given this evidence of the reliability of the phenomenon, the next question concerns its generality. The goal of Study 2 was to examine the effect on a larger scale to see whether affect incongruence would be found in real world evaluations.

\section{Study 2}

Yelp is currently one of the most well known business review companies. After patronizing a restaurant or other business, people can write reviews that appear on the Yelp website, and that include rating their experience with the business by giving between 1 and 5 stars. Yelp makes some of their data available for researchers. While Yelp does not ask about the affective states of reviewers, it is possible to use other data to infer something about the likely public mood at the time of the review.

One measure of such public sentiment is the Michigan Consumer Sentiment Index (MCSI; University of Michigan, 2016). The MCSI estimates the general sentiment about the economy of the people in the United States. Each month since 1964, researchers conduct 500 phone interviews from people in the U. S. (Hawaii and Alaska excluded) and ask questions about their view of the economy. Five questions make up the MCSI value and relate to beliefs about how people are doing right now economically and how well they expect to be doing in the future (See Appendix B for all 5 questions). In this study, the MCSI value will be used as a proxy for general public affect. While it is unlikely that the MCSI could be used to predict anything in a small lab sample, the volume of data accessible through Yelp should allow a good estimate of 
variation in public affect. The MCSI is updated monthly, which allows each Yelp review to be matched with the MCSI for the period when it was written.

Two analyses are of interest for this study. The first analysis asks whether there is evidence of the affect-congruence phenomenon. The second analysis asks whether there is evidence for an extremity effect. In Schiller (2014), people made more extreme responses when happy than when sad. If judgments show affect congruence, the level of public sentiment indexed by the MCSI would be positively related to the numbers of stars that reviewers gave during that period. Alternatively, public sentiment as measured by the MCSI might predict, not the mean number of stars (positivity), but the range (extremity) of the stars given during that period.

\section{Method}

Sample. The data consist of 4,146,335 million reviews of businesses on Yelp. The reviews were written between 2004 and 2017. The reviews were from cities Yelp selected. Of the 4.1 million reviews, 661,655 were from outside the United States (U.K.: Edinburgh, Germany: Karlsruhe; Canada: Montreal and Waterloo). The dataset does not contain standard demographic information (e.g., sex, age, et cetera). Mean star ratings and mean extremity (|stars 3|) were calculated and collapsed on each month of each year. Cells that contained fewer than 1000 observations were removed to avoid small cell counts having undue influence on the results.

\section{Results}

The initial analyses were performed on just the United States data $(3,484,680$ reviews). The MCSI values are created by calculating the mean of a series of measures for a given month. 
In the same way, the average number of stars and star extremity were calculated for each month. Data from 121 months were included in the U.S. data analysis. The first analysis looked at how well MCSI related to average stars. There was an effect of MCSI such that the higher the MCSI value, the higher the average stars, $b=.65, t(119)=9.38, p<.001, R^{2}=.42$ (See Figure 1).

\section{Yelp US Dataset: MCSI and Stars}

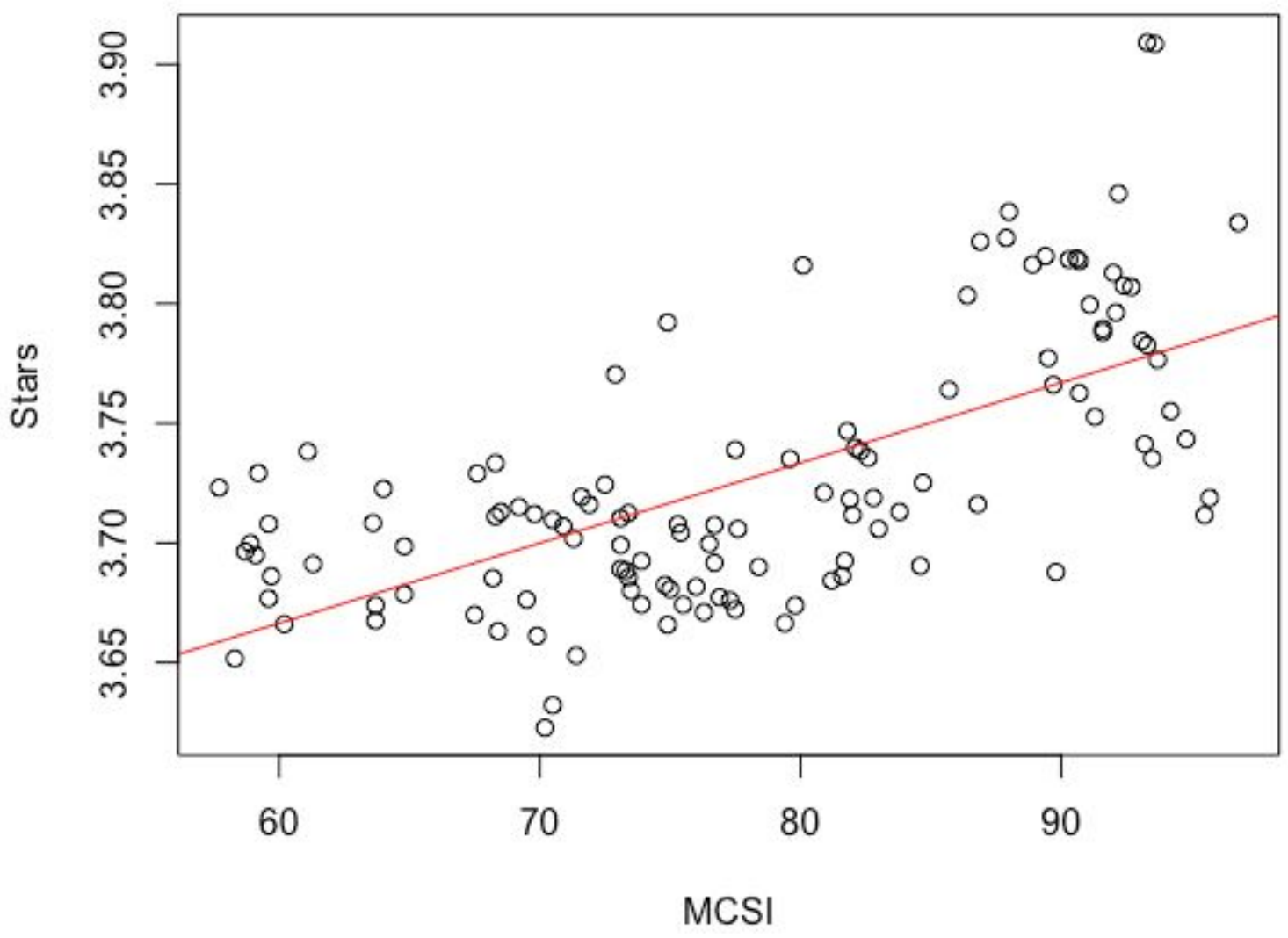

Figure 1. The relationship between MCSI and Stars. Regression line, $r=.65$.

While it is interesting that there is a relationship between MCSI and stars, more important is the relationship between MCSI and star extremity. MCSI also predicted an increase 
in star extremity, $b=.72, t(119)=11.38, p<.001, R^{2}=.52$ (See Figure 2$)$. It can be seen from the $\mathrm{R}^{2}$ values that the relationship between MCSI and extremity is stronger than the relationship between MCSI and average stars. In an ideal world this would be the end of the story, but further explorations of these data revealed a possible confounding variable: Time.

\section{Yelp US Dataset: MCSI and Extremity of Stars}

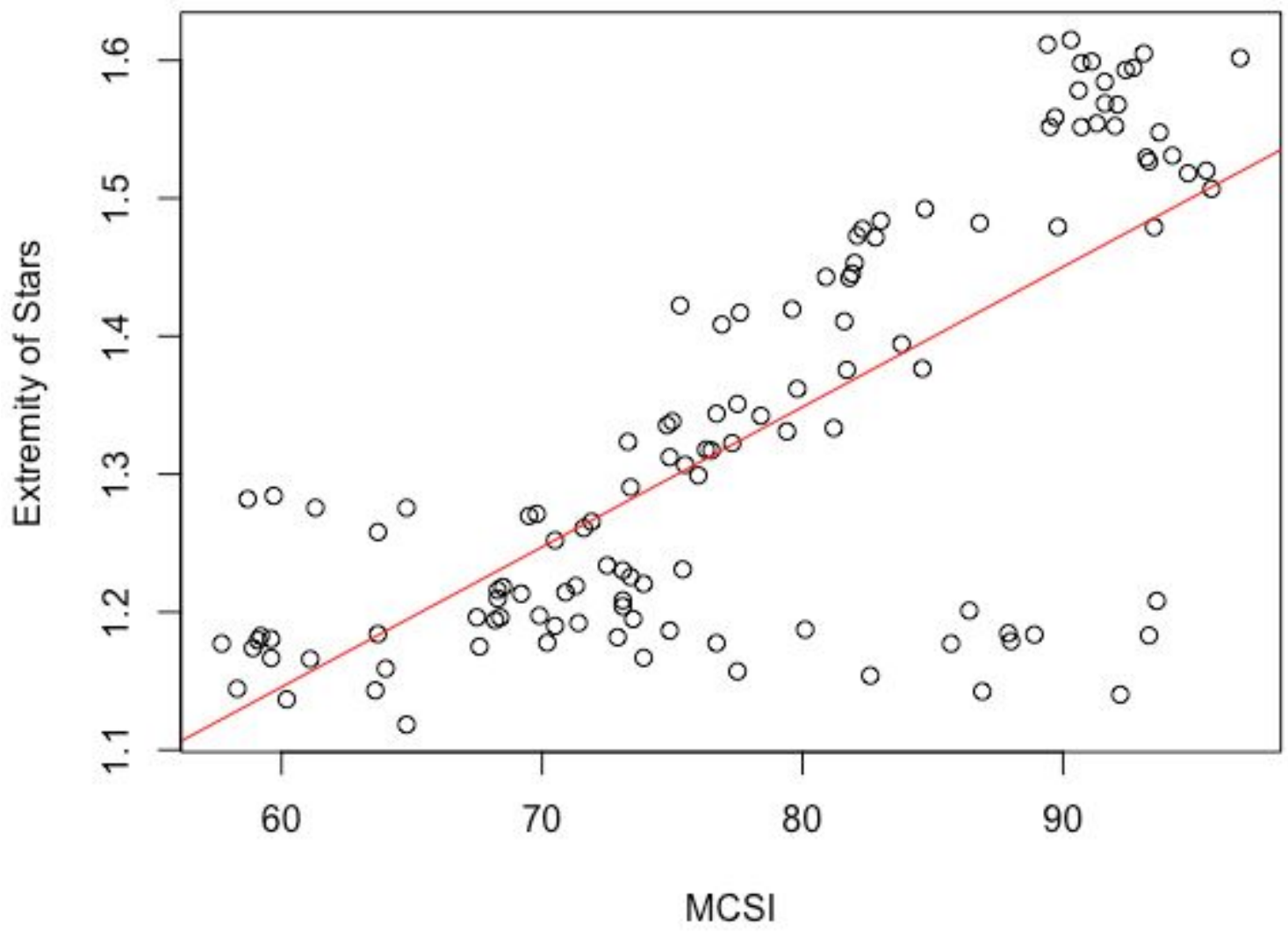

Figure 2. The relationship between MCSI and Extremity of Stars. Regression line, $r=.72$. 
Through deeper exploration of the data, it was found that while there was not a strong relationship between average stars and time $(r=.11)$, there was a strong relationship between star extremity and time $(r=.96$; See Figure 3$)$.

\section{Yelp US Dataset: Time and Extremity of Stars}

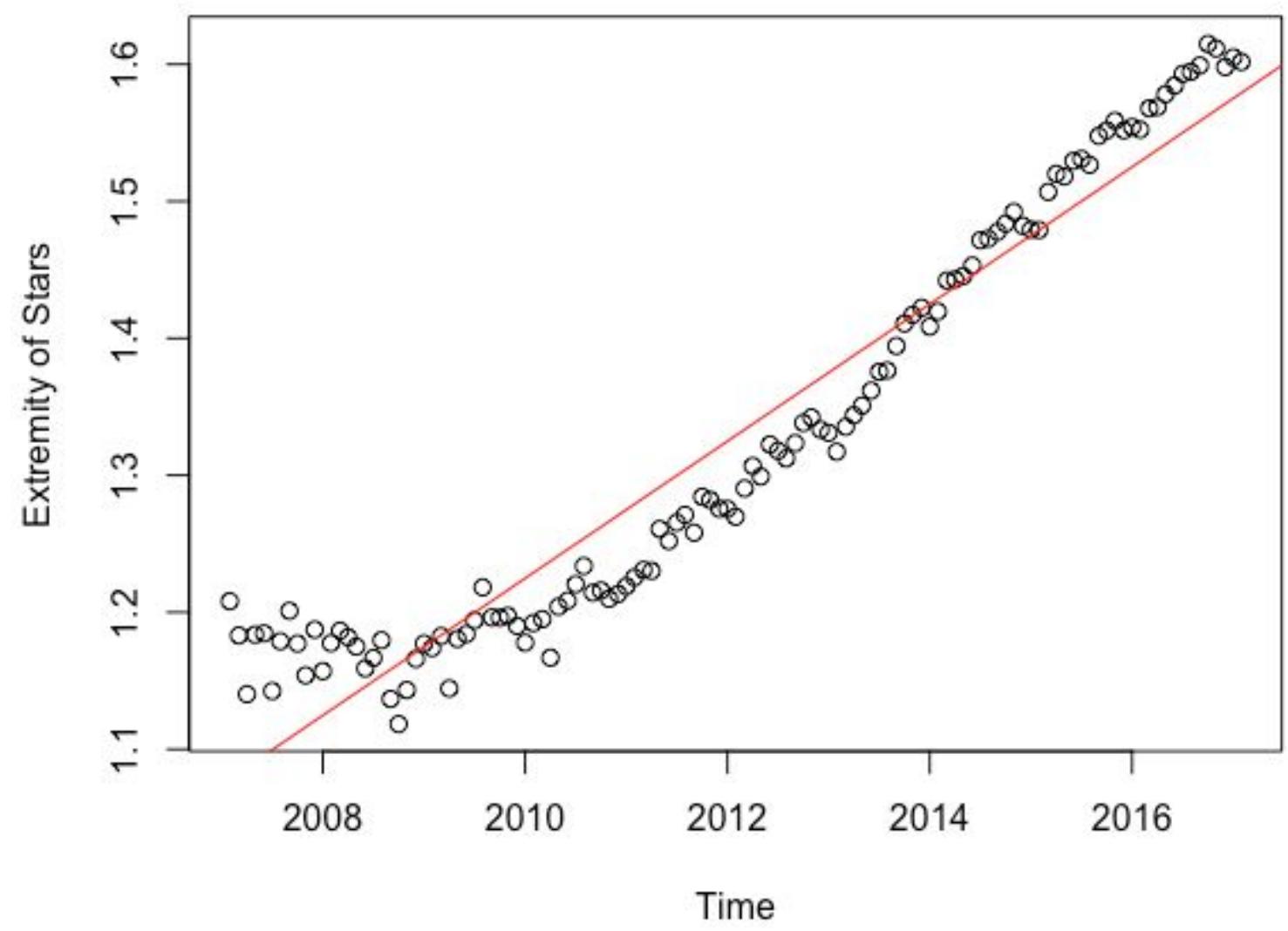

Figure 3. The relationship between Time and Extremity of Stars. Regression line, $r=.96$.

In the given time period, there was also a relationship between MCSI values and time $(r$ $=.58$ ). This very strong relationship between time and extremity, and the fairly strong relationship between time and MCSI raise the question of whether this result is purely a function of time and not of MCSI. The only true way to know is to wait for time, star extremity, and 
MCSI to diverge, but at least one attempt was made to delineate the effects of time and MCSI. A regression analysis was performed predicting the residual average star extremity after regressing out the effects of time. Even after controlling for the effects of time in this way, there was still a relationship between the residual extremities and MCSI, $b=.61, t(119)=8.39, p<.001, R^{2}=.37$ (Figure 4).

\section{Yelp US Dataset: MCSI and Extremity (Residuals after removing time)}

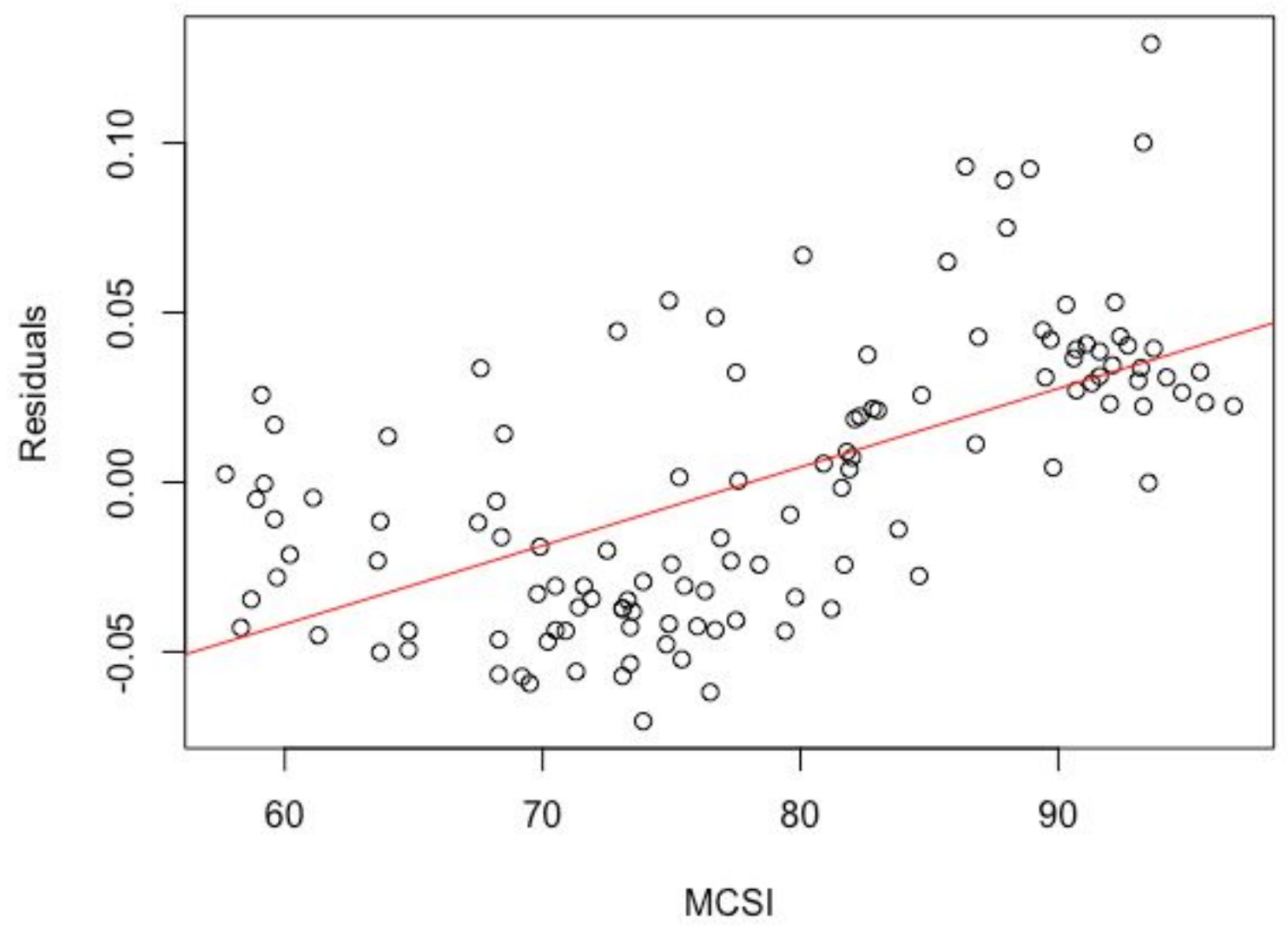

Figure 4. The relationship between MCSI and residuals of extremity after predicting time in the US dataset. Regression line, $r=.61$. 
While it is comforting that MCSI can still predict the residual values of rating extremity in the expected direction, the meaning of that result is questionable because of the high correlation, $r-.96$, between time and star extremity. Therefore, a second analysis was performed on the data collected outside the United States. While the United States and the outside countries all share economic ties, the consumer sentiment in the United States should not be as effective of a predictor of review extremity outside of United States. Time and review extremity were also highly related in the non-US data $(r=.90)$. A total of 100 timepoints were included in the non-US dataset after removing those with fewer than 1,000 reviews. Prior to removing the effect of time, MCSI was in fact a stronger predictor of review extremity in the non-US data, $b=.85$, $t(98)=15.50, p<.001, R^{2}=.73$. However, predicting the residuals after removing time in the non-US data completely negates the relationship between MCSI and review extremity, $b=.08$, $t(98)=.76, p=.45, R^{2} \approx 0$ (See Figure 5 ). These two results together point to MCSI as an effective predictor of extremity exclusive of the effects of time only in the country where it should be valid. These results, therefore, allay at least some of the concerns about time as a possible confounding variable. 


\section{Yelp Non-US Dataset: MCSI and Extremity (Residuals after removing time)}

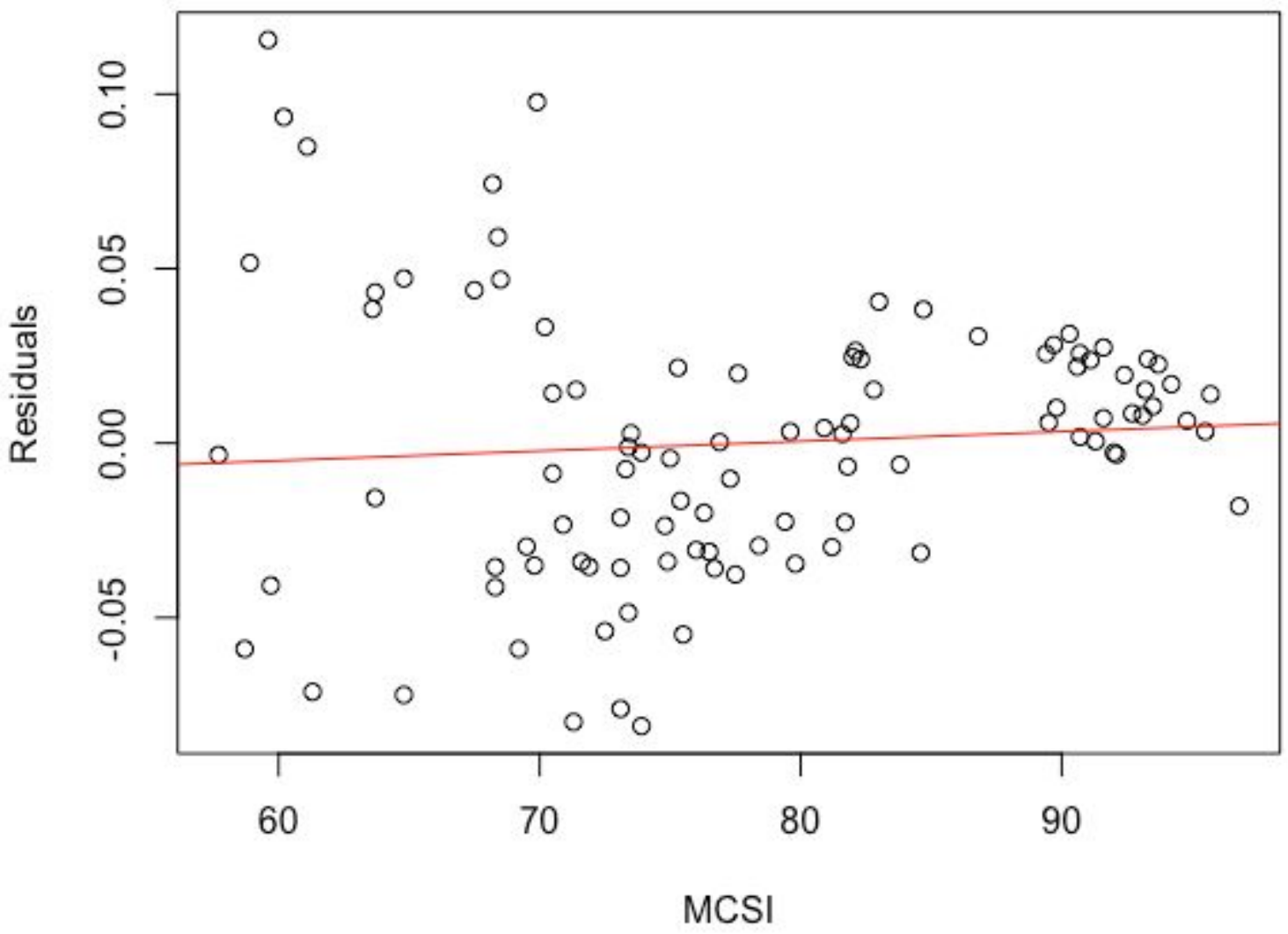

Figure 5. The relationship between MCSI and residuals of extremity after predicting time in the non-US dataset. Regression line, $r=.08$.

\section{Discussion}

In this massive dataset, there was some evidence that public sentiment led to affect congruency in the ratings, but there was stronger evidence that more positive public mood (MCSI) led to more extreme ratings. That is, when the economy was going well, people made more extreme evaluations of businesses. One confound was that extreme evaluations correlated with time, but this was in part overcome by first predicting extremity with time, and then 
predicting the residuals with MCSI. MCSI was still able to account for a large part of the residuals. Even more important, after controlling for time in a non-US sample, where an initially high relationship was found between time and star extremity (but where none would be expected) the initial relationship disappeared.

While Study 2 was not perfect, it highlights the complexity of working with real-world datasets, where there are many possibilities for spurious correlations or confounded relationships. It is still possible and even probable that other confounds exist and remain unaccounted for that could affect the results. As such, the analyses of Study 2 in particular should interpreted cautiously, and seen only one component of a larger narrative about the role of positive affect in extremity of response.

To recap, in Study 1, I found that evaluations of a decidedly negative target showed affect-incongruent evaluation, meaning that more positive moods led to more negative evaluations. The current study found results compatible with those of Study 1. Rather than leading to more positive evaluations, increases in public mood led to more extreme evaluations, presumably indicating that positive affect made those with initially positive inclinations more positive and those with initially negative inclinations more negative. In addition, the current work continues to be consistent with the persuasion work by Briñol and Petty (Petty \& Briñol, 2015) in that positive affect may increase reviewer confidence in their own review.

A drawback of this study (but not of Study 1) was the impossibility of knowing the starting opinion of each person before affect played a role in their evaluations. Study 3 was conducted to rectify this problem. The goal was to examine judgments in a case where prediction of the direction of participants' ratings was possible independently of their affective states. 


\section{Study 3a}

The first study of this dissertation, and most experiments in the literature on affect and judgment, involve small n's. Study 2 involved very large n's and found that positive public mood levels were associated with more extreme evaluative judgments. Study 3 investigated the same question in a large and more representative sample. The World Values Survey (2016) has been administered in various countries around the world since 1981. Six waves of data collection have been completed and are available for analysis. The first set of analyses in Study 3 was conducted on the most recent wave of data collection, Wave 6.

The goal of Study 3 was to see if the experience of positive affect enhances the beliefs that people already hold. Study 3 had the advantage over Study 2 that the survey included some cases in which multiple questions addressed similar domains so that answers to one question could be used to predict likely answers on a second question on the topic. In this case, life-satisfaction measures were used as a measure of general affect and were used to predict opinions about religion and science.

\section{Method}

Wave 6 Demographics. There were 86,272 people that completed Wave 6 of the World Values Survey. Of those, 8,777 were removed for not answering all three key questions (life satisfaction, faith vs. science, and religious status), leaving 77,495 people. The remaining sample were from 59 different countries with between 737 (Morocco) and 3,371 (South Africa) people completing the survey in each country $(M=1,313.47, S D=438.80)$. Ages ranged from 16 to 99 $(M=41.82, S D=16.45$, Missing $=95)$. There were slightly more women $(40,036 ; 51.70 \%)$ than men $(37,405 ; 48.30 \%)$ that completed the survey $($ Missing $=54)$. "Religious" participants were 
the most common, accounting for $67.4 \%$ of the sample, followed by "Not Religious" people accounting for $26.9 \%$, and "Atheists" with $5.7 \%$.

Measures. Survey respondents completed an extensive battery of questions related to their values with a survey administrator. For the analysis presented here, only three questions were of interest (See Appendix C for full question details). First was religious affiliation in which people classified themselves as a "Religious Person," "Not a Religious Person," or "An Atheist" (Additional questions about religious affiliation appeared in some waves, but only this question appeared in both Wave 6 and Wave 5). We used answers to the religion question as a way of predicting likely opinions on a second religion question, which was the primary variable of interest. The question was whether "We depend too much on science and not enough on faith." Finally, ratings of life satisfaction served as a measure of general affect. Satisfaction was assessed on a 10-point scale with the question, "All things considered, how satisfied are you with your life as a whole these days?" The question of interest was thus whether individual differences in the measure of affect (life-satisfaction ratings) would predict ratings on the Science vs. Faith question, given that respondents had already indicated that they were or were not religious. The prediction was that positive affect should enhance their initial opinions on the issue.

\section{Results}

Since there was no implied positive or negative valence in the faith versus science question, it is unclear what would constitute either affect congruence or incongruence. However, the hypothesis that positive affect reinforces existing beliefs predicts that individuals reporting high life satisfaction (positive affect) and who are atheists should be more likely to say science is 
more important than faith, and those that are religious should endorse faith over science. There was a significant main effect of religious affiliation such that Religious people $(M=5.71, S D=$ 2.79) depend most on faith, followed by Not Religious people $(M=5.16, S D=2.81)$ depending less on faith, and Atheists who depend the least on faith $(M=4.49, S D=2.93), F(2,77,489)=$ $587.44, p<.001$. There was also a significant main effect of life satisfaction such that those with higher life satisfaction said we need more faith than science, $F(1,77,489)=22.75, p<.001$. Finally, there was also an interaction effect such that religious people that were satisfied with their lives believed we needed more faith compared to those that were less satisfied, and Atheists that were satisfied leaned more toward science compared to Atheists that were less satisfied with their lives, $F(2,77,489)=19.91, p<.001, R^{2}=.012$. (Figure 6). 
Wave 6 Religious Affiliation, Life-Satisfaction, and Faith

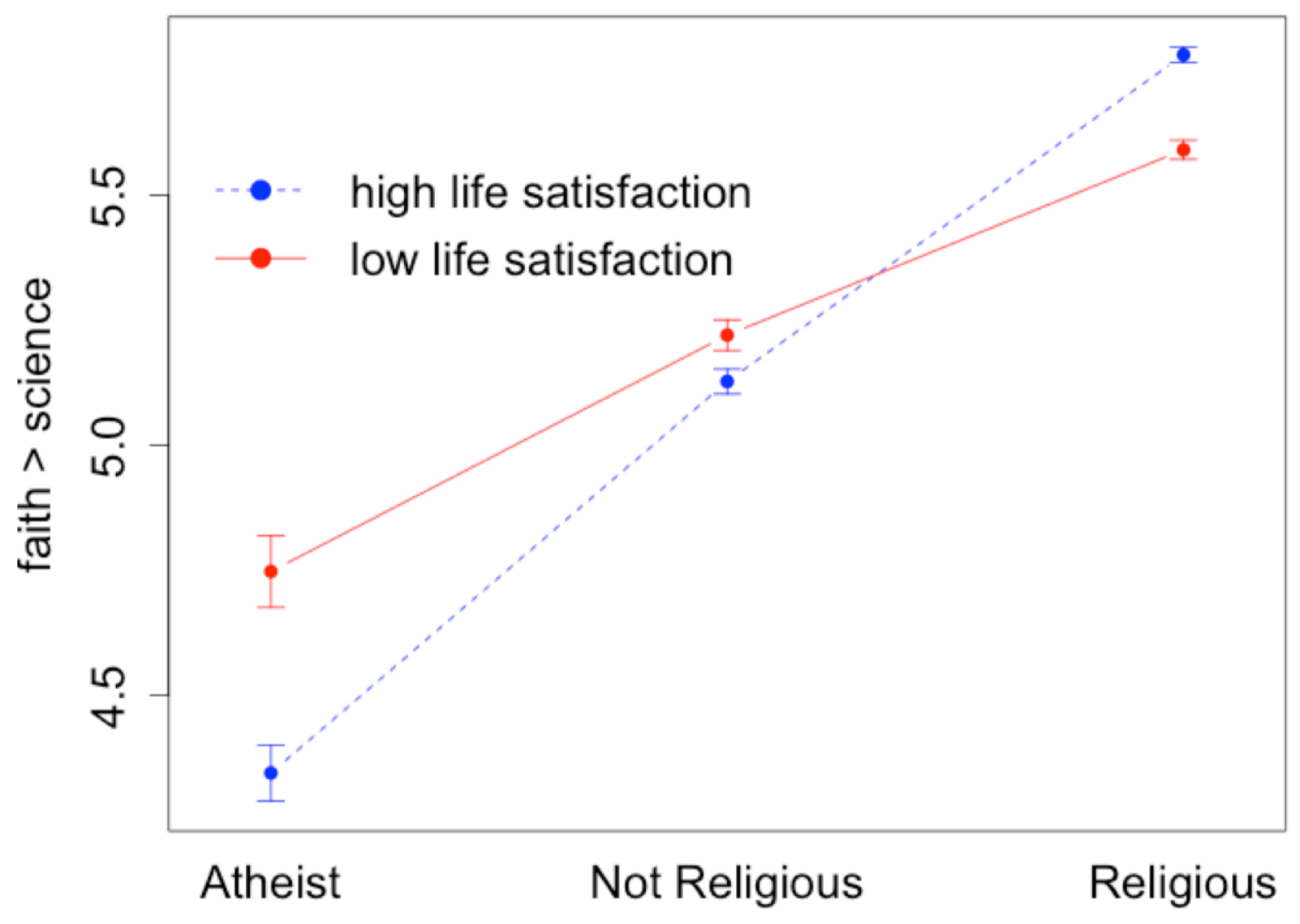

Figure 6. The relationship between religious affiliation, life satisfaction (median-split for presentation purposes), and desire for faith over science (higher numbers desire more faith) in Wave 6. Error bars $=95 \%$ confidence interval.

\section{Discussion}

The results of Study 3a showed that general affective states (indicated by ratings of life satisfaction) can influence extremity of responses in a large dataset that included individuals from more than 50 countries, a wide range of ages, and varied backgrounds. Given the many 
sources of variation in the sample, a large effect size would not be expected, and it is true that the effect size that was found was quite small $\left(\mathrm{R}^{2}=.012\right)$. These participants were from the most recent wave (Wave 6) of the World Values survey. To test the reproducibility of this finding, the same procedure was tested on another of the World Values Survey waves (Wave 5; Waves 1-4 did not include the faith versus science question).

\section{Study 3b}

\section{Method}

Wave 5 Demographics. Wave 5 contained 83,975 participants of which 23,666 were removed for not answering all of the critical questions, leaving 60,309 in the final sample. This wave contained participants from 47 countries $(M=1,283.17, S D=499.44)$. The fewest were from Bulgaria (783) and the most were from Colombia $(2,997)$. Ages ranged from 15 to 98 years old $(M=41.07, S D=16.25$, Missing $=170)$. There were more women $(31,040 ; 51.50 \%)$ than men $(29,237 ; 48.50 \%)$ in the sample (Missing $=32)$. The majority of participants identified as "Religious" (72.26\%), which was followed by "Not Religious" (23.05\%), with the fewest being "Atheist" (4.69\%).

Measures. See Measures for Study 3a.

\section{Results}

As in Study 3a, there was a significant main effect of religious affiliation where Religious people $(M=6.13, S D=2.97)$ depend most on faith, Not Religious people $(M=5.63, S D=2.84)$ depend less, and finally Atheists depend the least on faith compared to science $(M=5.03, S D=$ 3.04), $F(2,60,303)=305.45, p<.001$. Also consistent with Study 3 , there was a main effect of life satisfaction such that those high in life satisfaction favored faith more than science, $F(1$, 
$60,303)=29.88, p<.001$. Finally and again, as in Study 3 , an interaction between religious belief and life satisfaction indicated that individuals indicating high life satisfaction (positive affect) responded to the question concerning faith over science more extremely than did less satisfied individuals in the direction consistent with their religious beliefs, $F(2,60,303)=33.58$, $p<.001, R^{2}=.015$. (Figure 7). For example, respondents high in life satisfaction who were religious responded more extremely that they believed we should favor faith over science.

Wave 5 Religious Affiliation, Life Satisfaction, and Faith

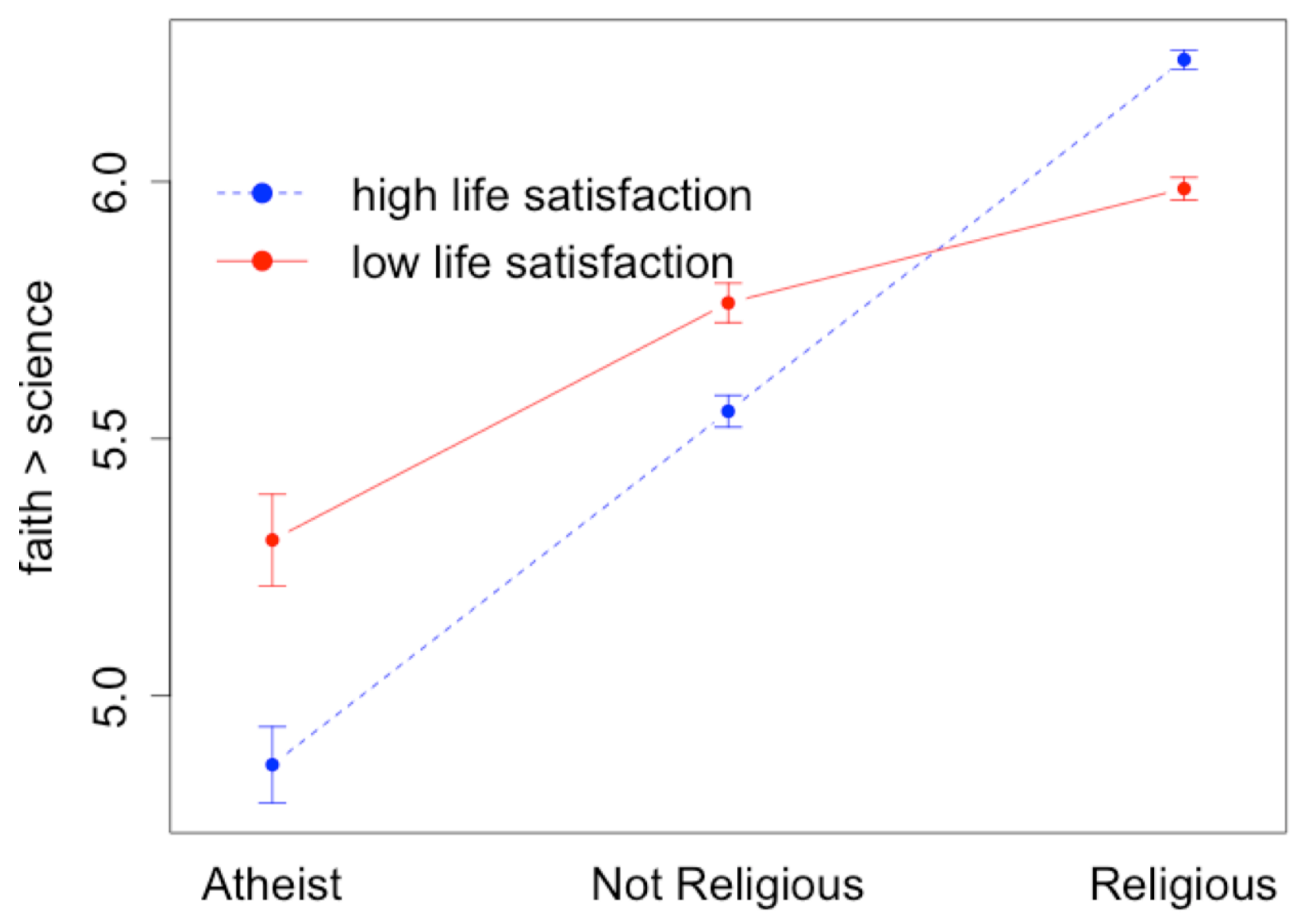

Figure 7. The relationship between religious affiliation, life satisfaction (median-split for presentation purposes) and desire for faith over science (higher numbers desire more faith) in Wave 5. Error bars $=95 \%$ confidence interval. 


\section{Discussion}

In line with Study 2, Studies $3 a$ and $3 b$ found that positive affect leads to more extreme responses. Importantly, the direction of the extremity was predicted by a third variable (religious affiliation) such that positive affect had the effect of reinforcing what people already believed rather than simply making any response more extreme. This finding was replicated in a second wave of data collection. In conjunction with Studies 1 and 2, Study 3 shows that not only does positive affect lead to more extreme judgments on the relevant issue, but the direction of the extremity was predicted by knowing a person's beliefs on a related issue. Again consistent with the work of Briñol and Petty (Petty \& Briñol, 2015), the current study is light-handed in comparison. There was no attempt at persuasion and no induced mood, only relying on beliefs the participants already held and life-satisfaction in lieu of mood. Together, these studies provide evidence of a new category of affective influences on judgment that go beyond the affect-congruence phenomenon, and which therefore require an explanation that can accommodate these new effects in addition to affective congruence.

\section{Study 4}

Study 3 used life satisfaction as a proxy for mood. Positive mood increased extremity of response on a science vs. religion item on the World Values Survey, and the effect replicated exactly in a second World Values Survey sample. The purpose of Study 4 was to see if this effect would emerge in another domain as well. Study 4 conceptually replicates the effects of Study 3 by using life satisfaction again as a proxy for mood and examining views of gun control. Specifically, Study 4 explored liberals and conservatives views on gun control using the American National Election Studies 2013 Internet Reconnect Study (ANES, 2013). 


\section{Method}

Participants. There were a total of five gun question, one political orientation question, and one life satisfaction question used in the analyses. Of the 1,635 participants who completed the study, 1,441 (681 women, $\left.M_{\text {age }}=53.79, S D_{\text {age }}=16.00\right)$ answered all 7 questions and were included in the analyses.

ANES 2013 Reconnect Demographics. In total 1,635 people completed the ANES 2013 Reconnect survey. Of those, 194 were removed for not answering all seven key questions (5 gun control questions, life satisfaction, and political orientation), leaving 1,441 people in the sample. Ages ranged from 18 to $92(M=53.79, S D=16.00)$. There were slightly fewer women $(681$; $47.26 \%)$ than men $(760 ; 52.74 \%)$ that completed the survey.

Measures. Survey respondents completed a battery of questions related to their political values online. For the analysis presented here, only seven questions were of interest (See Appendix D for full scale information). First was political orientation on a 7-point scale (Very Liberal to Very Conservative). The orientation question was used to infer views on the second variable of interest: gun control. Participants in the survey answered 5 questions about gun control on a 3-point (favor, neutral, against) scale. Finally, ratings of life satisfaction were used as a measure of general affect. Satisfaction was measured on a 5-point scale with the question, “All things considered, how satisfied are you with your life as a whole these days?" The question of interest was whether individual differences in the measure of affect (life-satisfaction ratings) would predict ratings on the gun control questions, given the participants' political leanings. Consistent with Study 3, the prediction was that positive affect should enhance initial opinions.

\section{Analyses}


There is one analysis of interest: the interaction between political orientation and life satisfaction predicting views on gun control. Unsurprisingly, there was a significant effect of political orientation such that liberals favored more gun control, $F(1,1,437)=170.22, p<.001$. There was also a main effect of life satisfaction, with happy (high life satisfaction) people being more pro gun control, $F(1,1,437)=22.11, p<.001$. Most importantly, there was an interaction between political orientation and life satisfaction, with happy conservatives being more against gun control than unhappy conservatives, and happy liberals being more pro gun control than unhappy liberals, $F(1,1,437)=43.10, p<.001$ (See Figure 8). Individual analysis of each of the 5 gun questions revealed a consistent pattern of results (See Appendix E for analysis and plots for each question individually). 


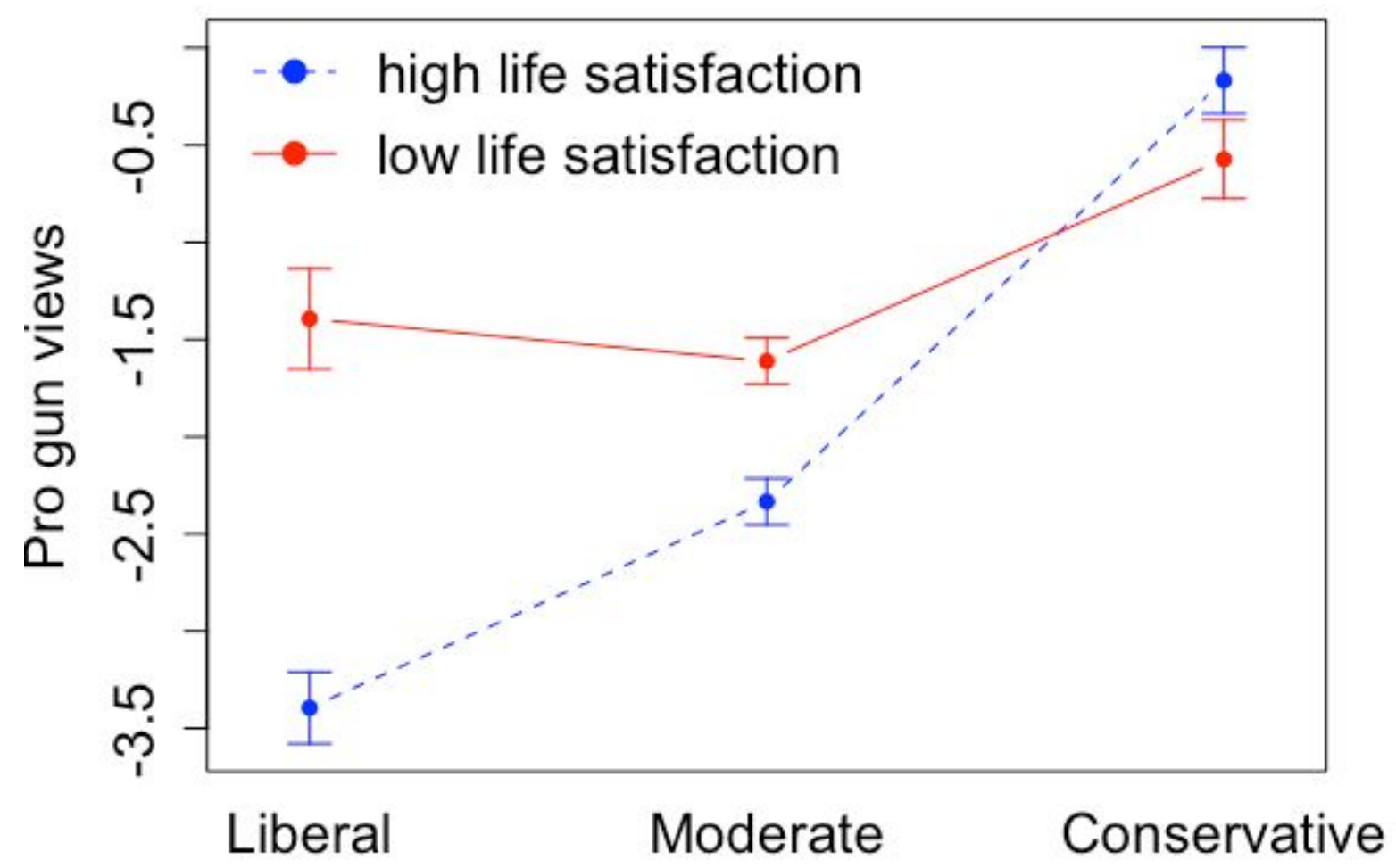

Figure 8. The relationship between political orientation (grouped liberal [1-2], moderate [3-5], conservative [6-7]), life satisfaction (median-split) and views on gun control (higher numbers are more pro-gun [anti-gun control]) in the ANES 2013 Internet Reconnect study. Error bars = 95\% confidence interval.

\section{Discussion}

Happy people appear to reinforce their beliefs and unhappy people appear to dampen their beliefs. This was consistent with the results found in all the previous studies showing that when people have a given belief and are happy they are more likely to move in the direction consistent with their belief. In conjunction with the previous studies, Study 4 demonstrates again that general affect can act as a reinforcer of previously held beliefs. One remaining question is 
whether value can be manipulated instead of measured, and still yield results consistent with this positive affect intensification effect.

\section{Study 5}

The previous four studies found that affect can lead to affect-incongruent responses, extreme responses, and stronger versions of prior beliefs, none of which can be described as instances of affective congruence. Study 1 found that induced affect can lead to affect-incongruent evaluation when the target of judgment is negative. Study 2 showed that in a large dataset, a proxy for public mood was associated with stronger evidence for extremity of evaluation than for affect congruence. In Study 3, which used reports of life satisfaction as a measure of positive affect, individuals high in life satisfaction made judgments that were more consistent with their existing orientations than did individuals low in life satisfaction (negative affect). Study 4 conceptually replicated Study 3 in a new sample, demonstrating that high life satisfaction intensified politically relevant beliefs about gun control. These four studies together indicate that affective variables play a role in evaluation and judgment that is not readily explained by existing accounts.

The primary weakness of the studies covered thus far is that only one study contained an experimental manipulation. A strong test of the conditions under which affect-congruence occurs would involve manipulating both the starting valence of the target of evaluation and mood. Another variable of interest is the presentation order of the mood induction and the value information about the target of evaluation. In the studies discussed so far, the order was not explicitly considered but did vary. There are three ways in which the order can vary. The first variation occurs when information about the target of evaluation is explicitly presented prior to 
the mood induction. For example, Study 1 included a paragraph about Alex Rodriguez' current doping scandal before mood was induced. The second variation occurs when thoughts about the target are activated at the time of evaluation. The evaluation of Lance Armstrong's

LIVESTRONG bracelet in Schiller (2014) occured after a mood induction and nothing about the target of evaluation was discussed until participants were asked to make an evaluation. The third variation is when information about the target is explicitly presented after a mood induction but prior to evaluation. This third variation has not been explored while also manipulating target valence and mood.

The order in which information about the target is presented will vary in Study 5. One possible outcome is that this order variation will not have an influence on evaluation. This is a plausible outcome because Study 1 and the Lance Armstrong study in Schiller (2014) used two different variations of order and found comparable results. However, neither study involved directly manipulating target valence, so it is also plausible that order will matter when new information is presented after an induction. In a review of studies of affect and persuasion, Petty and Briñol (2015) conclude that when affect comes before persuasive messages, it is likely to be experienced as a reaction to the message, but when affect comes after persuasive arguments, it is likely to be experienced as a reaction to thoughts about the messages rather than the messages themselves. The key appears to lie in the implicit attributions for affect, which depend on whether the messages or participants' thoughts are more accessible when affect is induced.

If order does influence the results in the current judgment paradigm, it is possible that belief reinforcement will only occur when information about the target of evaluation is presented prior to the mood induction. When a target is introduced after mood it is possible that 
affect-congruence will occur because the new target information would be evaluated through the lens of the induced mood. Either outcome could help clarify the role of mood and thoughts in evaluation.

\section{Method}

Participants. In total 345 people were recruited for payment on Amazon's Mechanical Turk. Exclusion criteria for participants matched that of Study 1 (Alex Rodriguez) and Experiments 1 and 2 of Schiller (2014). In addition, participants that read the story about John for fewer than 10 seconds were excluded. After exclusions, data from 276 participants (112 women; $\left.M_{\text {age }}=35.52, S D_{\text {age }}=11.59\right)$ made up the final sample. The smallest cell of the 2 (Mood) x 2 (Order) x 2 (Evaluated person valence) design contained 36 participants (Sad; Mood first; Person positive) and the largest contained 48 participants (Happy; Mood first; Person negative).

Procedure. The participants read a description of a person, John. There were two versions of the descriptive passage that were the same except for the last line, which contained slightly positive or slightly negative information, as follows:

John grew up in a small town in the Midwest. His father was a construction worker and his mother was a nurse. John generally did well in school, but also was prone to mischief when he was younger. After college, John worked his way up in a non-profit and now manages a small team of 10 employees.

John's neighbors describe him as friendly and quick to smile. His subordinates value his experience, but noted that his critiques can come off as blunt. John is very studious in his free time, often reading historical non-fiction 
books. Recently there was an emergency situation at John's work. John's coworkers noted that in his reaction he was calm and decisive. [In the negative version: "John's coworkers noted that in his reaction he was tense and indecisive.”]

All descriptive words were drawn from Anderson's 555 personality trait words (Anderson, 1968). For example, both conditions described John as friendly (positive), experienced (positive), blunt (negative), and studious (positive). The positive condition further described him as calm and decisive, whereas the negative condition described him as intense and indecisive. After one of the two descriptions, participants were asked to remember the description until later. They also completed a brief mood induction that was the same as in Study 1 (Variable 2: Mood). Participants completed the mood induction either before or after reading the vignette about John (Variable 3: Order). Once the mood induction and the vignette were completed, participants reported their liking of John on two scales (See Appendix F). Finally, participants filled out demographic information, answered questions about the mood induction, and read a debriefing form.

\section{Analysis}

Mood Manipulation Check. Two items were used to assess the mood of the participants (5-point scale: Not at all, A little, Somewhat, Moderately, Very): "How happy did you feel while writing?" and "How sad did you feel while writing?" As expected, individuals in the happy group reported feeling happier than those in the sad group $(M s=4.29,1.40, S D s=.84, .83)$, $t(274)=28.68, p<.001$, and those in the sad group reported feeling more sad than those in the happy group $(M s=3.66,1.24, S D s=.58,1.16), t(274)=22.02, p<.001$. 
Person Ratings. The goal of the study was to determine how explicitly manipulated starting values interact with experimentally manipulated mood, and mood order such that positive moods reinforce the starting value. The primary analysis of interest was a 2 (positive and negative starting value) $\times 2$ (positive and negative mood) $\times 2$ (mood induction first or second) ANOVA. First, as expected there was a difference between the vignettes, such that people rated the positive vignette more positively than the negative vignette, $F(1,268)=39.86, p<.001$. Additionally, there was an effect of mood, such that happy participants evaluated the target more positively than sad participants, $F(1,268)=4.16, p=.042$. Surprisingly, there was no effect of order, no 2-way interactions, and no 3-way interaction, $F$ 's $(1,268)<2.33$, p's $>.05$ (See Figure 9). While the lack of any interaction was unexpected given the previously presented studies, the previous literature presents a precedent for such a result. 
Induced Mood, Positive/Negative Vignette, and Evaluation of John

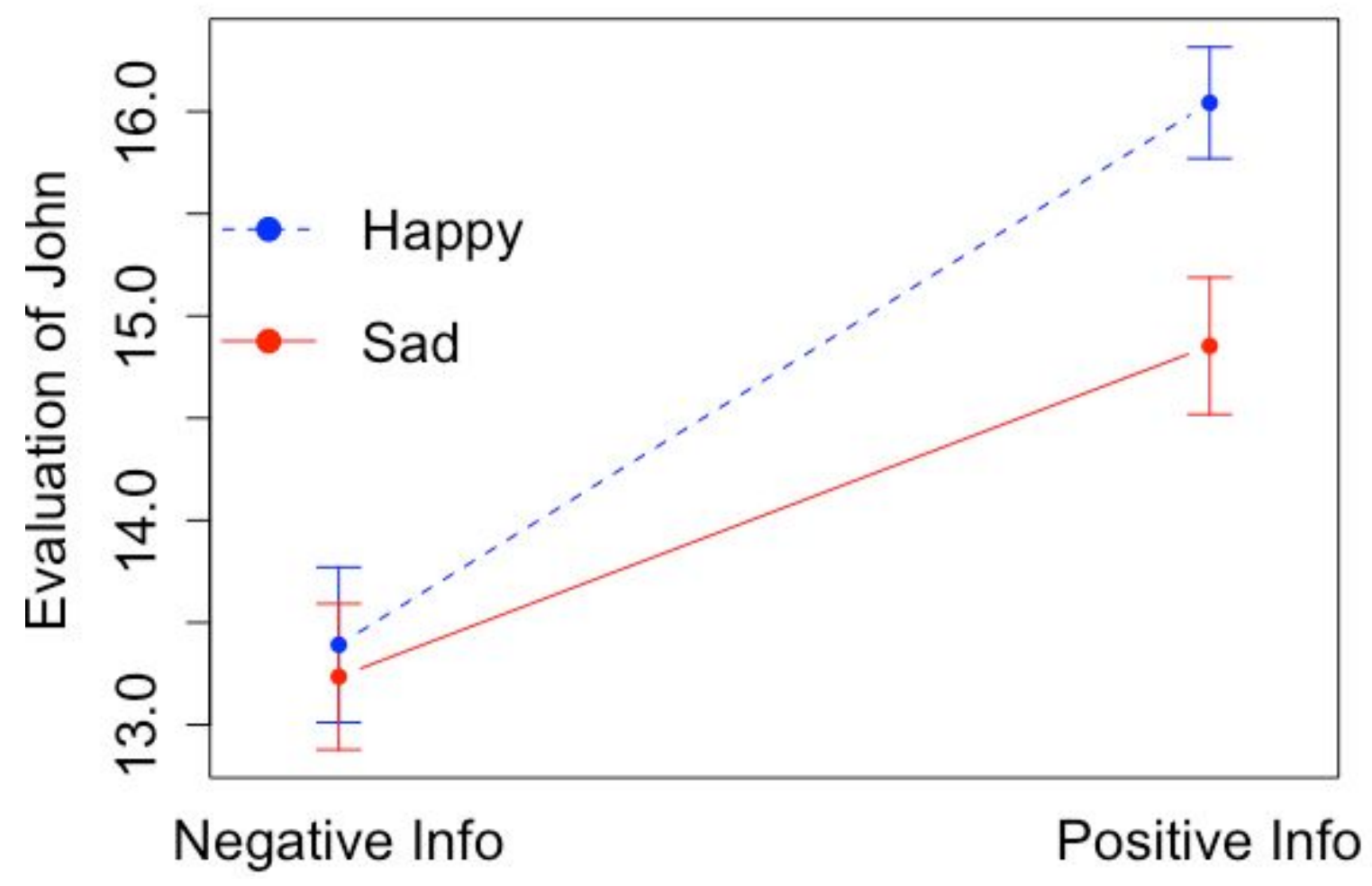

Figure 9. The relationship between mood and positive/negative information vignettes on evaluations of vignette targets 'John'. Error bars $=95 \%$ confidence interval.

\section{Discussion}

In each of the previous four studies, affect did not lead to results consistent with the affect-congruent evaluation hypothesis. In Study 5, however, affect led to a result consistent with affect-congruent evaluation. The results of Study 5 outside of the context of the previous 4 studies might be viewed exclusively as evidence of affect congruence. Armed with new data, this result is neither unexpected nor contradictory. 
The primary difference between Study 1 and Study 5 is that Study 1 relied on an already negatively biased target and found that happy people evaluated this target to be more negative than those in a sad mood. Study 5 attempted to vary the positivity of the target by using two vignettes that varied in their level of positivity. The strongest main effect found was in the difference between the two vignettes, with the positive vignette leading to more positive evaluations of the target compared to the negative vignette. The difference between the two vignettes ensures that the manipulation was successful in changing the base evaluations. Despite finding a difference, one concern that emerges is that the negative vignette may not have been negative enough to elicit affect-incongruent evaluation as in the previous studies. Finding the balance between sufficiently positive and negative information requires great care. Including any single piece of information that is too valenced can lead to effects based solely on one attribute. For example, John may be a deacon in his church, devote all his time to charity, and be overwhelming positive in every regard except for the fact that he is addicted to internet pornography. Any negative signal in a description, without extensive context can taint an otherwise good-sounding person.

Study 5 brings the current work full circle. A large body of evidence has shown affect-congruent evaluation in a variety of contexts. One claim made in the current studies is that the direction and valence of the initial evaluation is an important part of understanding the role of affect in evaluation. The current results show that minor variations in starting valence can still lead to affect congruence. That result helps clarify the conditions under which affect-congruence and incongruence can occur, but further work on tuning the positivity and negativity of the context is needed to understand when the effect flips from congruence to incongruence. 


\section{General Discussion}

Five studies explored the role of affect in evaluation and judgment. The current literature concerning the influence of affect on evaluation says that people tend to evaluate objects in an affect-congruent way (e.g., Isen et al. 1978; Schwarz \& Clore, 1983; Srull, 1983). Of five studies conducted, four revealed a different pattern of results in which mood led to affect incongruence, greater extremity of response, and enhancement of existing beliefs. One study contained results consistent with an affect congruence approach. These new results make it clear that affect congruence is only one the patterns of results that can emerge when affect influences evaluation.

\section{A more complicated phenomenon}

To recap, affect congruence in evaluation is a well-established phenomenon (e.g., Isen et al. 1978; Schwarz \& Clore, 1983; Srull, 1983). The literature shows that people often evaluate the world in ways that are consistent with their current affective state. While affect congruence has been shown in many studies, the current work shows that this is not the only pattern of results that can occur. Three other patterns of results were shown that are inconsistent with the standard pattern of affect congruence, including affect incongruence and patterns in which positive and negative affect leads to greater or lesser extremity of rating and greater or lesser belief enhancement.

The first inconsistent finding was one of affect-incongruent evaluation. In Study 1, participants induced to be happy or sad rated their liking of an Alex Rodriguez poster shortly after his steroid use was exposed. If the data conformed to the affect-congruence phenomenon, happy mood should lead to greater liking of the poster of Alex Rodriguez than sad mood. Contrary to that affect-congruence prediction, happy mood led to less liking of the poster than 
sad mood. This affect-incongruent finding was a conceptual replication of a study in Schiller (2014) that also showed less liking of LIVESTRONG bracelets associated with Lance Armstrong after he was caught in a doping scandal. Together, these two findings provided preliminary evidence that the affect-congruent phenomenon was not as general as previously thought.

The second finding that was inconsistent with an affect-congruence pattern was that the primary influence of affect in Study 2 was on the extremity of evaluations rather than their mean value. Study 2 related a large dataset of online business reviews to a measure of public mood. An affect-congruent pattern would have been that more positive public mood was associated with more positive business reviews. While a small affect-congruence effect emerged, there was a much larger effect such that the more positive the public mood, the more extremely businesses were evaluated. In other words, when public mood was positive, people were more likely to rate businesses either more positively or more negatively (presumably dependent on their unknown initial opinion). This extremity of response finding was consistent with a study in Schiller (2014) that showed happy mood led to more extreme ratings of life satisfaction than sad mood. Both studies found small affect-congruence effects but larger extremity of response effects. In conjunction with the studies showing affect-incongruent evaluation, these studies show the lack of generality of the affect-congruence pattern.

The third pattern of results is one of belief enhancement. Study $3 a$ analyzed evaluative judgments concerning a statement that people should depend more on faith than on science. Responses to another question about religious affiliation were used to predict the direction of responses to the question about whether people should emphasize faith over science. In that study, individuals' life-satisfaction ratings were used as a proxy for their general affective state. 
Since the dependence on faith over science item has no inherently positive or negative pole, questions of affect congruence do not apply. But the results were clear in showing that high life satisfaction (positive affect) was associated with stronger expressions of the opinions that religious and nonreligious respondents were expected to hold. In other words, religious people with high life satisfaction thought people should depend more on faith, and atheists with high life satisfaction thought people should depend more on science. This result was replicated in another wave of the survey using the same measures (Study $3 b$ ). This result was again replicated conceptually in a different dataset showing that high life satisfaction liberals were more anti gun than low satisfaction liberals and that high life satisfaction conservatives were the more pro gun than low satisfaction conservatives (Study 4).

In the final experiment, when affect and the valence of the target were directly manipulated, a result matching affect-congruence was found (Study 5). While these data were inconsistent with the previous four studies, they do match the previous literature showing affect-congruent evaluation. Despite being consistent with affect congruence, they are not inconsistent with a belief reinforcement view. When evaluation is not sufficiently negative, it is still possible to find a pattern that looks like affect-congruence as the already positive evaluations are further enhanced by positive affect. Study 5 demonstrates that the original affect-congruence finding is replicable under the right conditions within the design used in Study 1, but that those conditions are not yet perfectly understood.

Together, the studies from Schiller (2014) and the present work show that affect congruence is a less general principle than has been assumed in the literature, but it can still be achieved under certain circumstances. Each of the studies presented show a different kind of 
influence that affect can have on evaluation and judgment. A sufficient explanation for how affect influences evaluative judgment must account for all of the different patterns of judgment observed here, from the standard affect-congruence pattern to the newly found pattern in which positive affect intensifies expressions of existing opinions and beliefs. How well do the previous explanations that generally assume affect congruence hold up with these new data?

\section{Explanatory power of the belief enhancement hypothesis}

Neither the memory hypothesis nor the affect-as-information hypothesis predict all four patterns of results (affect congruence, affect incongruence, extremity, and belief enhancement). Their absence of relevant predictions is not surprising, as they were designed to explain affect congruence alone. Both hypotheses explain affect congruence by assuming that what affect does is to modify the value of the object of evaluation. The memory hypothesis claims that this occurs by activating memories about the target that are consistent with the current affective state. The affect-as-information hypothesis says that modification occurs when the current affective state is attributed as a reaction to the target of evaluation. Both hypotheses assume that the target of evaluation gains or loses value based on the valence of the associated affect.

Both the memory and affect-as-information hypotheses assume that what is affected is the value of the target of the evaluation (e.g., a refrigerator, as in Isen, et al., 1978). However, many thoughts and beliefs may come to mind while making an evaluation of a judgment object. Might affect be modifying the value of these thoughts and beliefs instead of directly modifying the target of evaluation? In other words, does affect modify the value of thoughts about the quality of a refrigerator instead of the value of the refrigerator directly? The Affect Immediacy Principle from the affect-as-information approach (Clore, et al., 2001) says that affect serves as 
information about whatever is in mind at the time. Affect could be used as information either about the target of evaluation or about the thoughts and feelings stimulated by the target of evaluation. The key should be simply that the object of affect is likely to be whatever is most accessible in mind at the time. If so, the influence of affect is not limited to being about the nominal object of judgment, but may influence whatever object or thought is in mind (Clore \& Huntsinger, 2009). Various thoughts and feelings may pass through the mind while considering the quality of the target of evaluation, and these thoughts or beliefs can therefore become the object of affect. In fact, each of the four patterns of results can be explained by considering how affect might modify evaluations of beliefs about the target instead of evaluations of the target directly.

How does allowing beliefs to become a target of affect explain affect-congruent evaluation? Take, for example, the classic work of Isen et. al (1978) in which people given small gifts evaluated their appliances more favorably. Unless a person's appliance is not working properly, most people probably have a mildly positive view of their appliances. If the object influenced by affect is the appliance, then happy people will like their appliance more than sad people, as happiness is adding positive value directly to the target (the appliance). What happens when the object of affective influence is the person's beliefs about the appliance? Then happiness should add value to the mildly positive beliefs about the appliance, and the final evaluation should still be more positive. In fact, when thoughts and beliefs about the target of evaluation are positive, the final evaluation should be similar regardless of whether the target or thoughts about the target are the object that affect modifies. As a result, when thoughts about the target are positive, the results will appear consistent with the affect-congruence phenomenon. 
How does allowing beliefs to become a target of affect explain affect-incongruent evaluation? When the starting beliefs about the target of evaluation are generally negative, affect-incongruent evaluation can occur. Affect-incongruent evaluation was found when a disliked target was evaluated (Alex Rodriguez in Study 1; Lance Armstrong in Schiller, 2014) . Instead of happiness adding value to the target of evaluation, the positive affect reinforced the negative beliefs connected to the target of evaluation (e.g., Alex Rodriguez is a cheater). When the target of evaluation is consistently negative, it should be possible to find affect-incongruent evaluation.

How does allowing beliefs to become a target of affect explain extremity effects? When the initial beliefs about the target vary widely and are unknown, the belief-as-object idea predicts that positive affect should increase, and negative affect should decrease, the extremity of evaluations. When some initial beliefs start out negative and others start out positive, then positive affect cues will reinforce the value of the belief, in a direction that is consistent with the initial belief. With a completely even distribution of positive and negative beliefs, no standard affect-congruence effect would be expected, and only an extremity effect should occur. With a positively-biased range of evaluations like the Yelp reviews in Study 2 and life-satisfaction ratings in Schiller (2014), a small affect-congruence phenomenon can be expected. However, this small affect-congruence effect is outclassed by the size of the extremity effect in both cases. If the starting point for each person's beliefs were known a priori, then extremity would be a poor way to analyze these data. The point is not that affect leads to more extreme response, but that affect reinforces the beliefs a person had before making their evaluation. Together, when the 
target of evaluation is positive for some raters and negative for others, then overall one should find more extreme ratings.

How does allowing beliefs to become a target of affect explain belief enhancement?

When the starting beliefs about the target of evaluation are known, then positive affect should lead to belief enhancement. In fact, the belief enhancement pattern of results can explain all of the other patterns of results discussed (affect congruence, affect incongruence, and response extremity). Finding evidence for the belief enhancement pattern requires knowing the person's initial beliefs and having in the data a diversity of initial opinions or beliefs. These conditions were satisfied in Study 3 because knowing the religious orientation of respondents allowed me to make clear predictions about how affect should influence their evaluations of the assertion that people should depend more on faith than science. Study 4 conceptually replicated this pattern in which positive affect enhanced beliefs. That is, happy respondents were more extreme in their beliefs about gun control, a finding made possible by knowing their general political orientation. In sum, each of these patterns of data can be explained by taking into account the starting value of respondents' beliefs and their affective state.

\section{Status of the memory and affect-as-information hypotheses}

Neither the memory nor the affect-as-information hypotheses include the idea that affect might have its effects on evaluations of beliefs about targets of evaluation rather than on evaluations of targets themselves. However, since both hypotheses focus on the role of affect in modifying the value of a target of evaluation (albeit through different means), there is no reason they could not incorporate the possibility of beliefs being the object that affect modifies. 
Furthermore, none of the data directly speak to the validity or invalidity of either hypothesis beyond the fact that neither anticipate the current findings.

\section{When does affect act on the target of judgment and when on beliefs about the target?}

While the present data seem to indicate that affect modifies beliefs about targets of judgment instead of targets of judgment directly, it is likely that what affect modifies is dependent on the context of the evaluation. The Affect Immediacy Principle, which is compatible with the belief enhancement idea, is that affect serves as information about whatever is in mind at the time (Clore \& Huntsinger, 2009). Unfortunately, it is difficult to know exactly what is in anyone's mind at a given moment. Even within the same study, it is possible that some people are using affect as information about the target of evaluation, and others are using affect as information about their beliefs. The purpose of the present work is not to determine when affect serves as information about targets versus beliefs. While the current data are best described by assuming that affect modifies beliefs about object of judgment, at a larger level, they are not necessarily inconsistent with the idea that affect can also influence targets of evaluation directly.

\section{Belief Enhancement and Thought Confidence}

One area where future work might focus is on differentiating affect-reinforcement and thought confidence as proposed by Briñol and Petty (Petty \& Briñol, 2015). I argue that affect serves as a source of information about thoughts, whereas Briñol and Petty argue that (positive) affect increases confidence in thoughts. While the two are quite similar, I believe there is a subtle difference that may be highlighted by looking at two separate parts of the process: the assignment of value and the confidence in that choice. The studies in this dissertation showed that affect can change how value is assigned. Positive affect can lead to a more negative 
judgment, but what was untested in the current work is whether it also influences the confidence one has in those responses. Briñol and Petty (Petty \& Briñol, 2015) have shown that confidence in responses can change as a function of induced mood, but whether there is also a change in the value of the stimulus responded to is not entirely clear. Demonstrating that valence and confidence can move independently (and showing that one follows the other) would help clarify the underlying mechanisms at work. For example, if valence can move, but confidence stays the same, an argument could be made that affect primarily influences valence and not confidence. Alternatively, if valence can be shown not to move, but confidence does, then the opposite may be true. The more likely outcome is that there is a complicated interplay between evaluation and confidence, with each reinforcing the other under a variety of circumstances. A thorough understanding would help clarify the role of affect in evaluation and how value arises.

\section{Contrast Effects}

One commonly proposed characterization of results like those in the current studies invokes the idea of contrast effects. Contrast effects involve changes in the value of one object in contrast to the value of another object on the same dimension. For example, a light color patch will appear lighter if next to a dark color patch merely by having a darker patch in close proximity. A contrast effect explanation for Study 1 might be that when a person feels happy, the badness of Alex Rodriguez (and his poster) appears worse because they currently feel happy, leading them to evaluate his poster more harshly in contrast. While this interpretation may seem sensible, further consideration shows that it encounters a number of problems.

One goal of the current work is to be able to predict all of the affect-influenced evaluation findings within a single framework. Whereas a contrast effect explanation may explain a single 
study, it falls short when considered in the context of all of the data. A contrast effects explanation cannot handle standard affect-congruence effects because it predicts that sad mood should make objects seem more positive than happy moods, which is not always the case. Furthermore, a contrast effects explanation cannot explain the increased extremity of ratings in happy moods (Study 2) or the enhancement of views by positive affect (Studies 3 and 4). Despite its appeal, a contrast effects explanation can be readily discounted as a general account of how affect influences evaluation.

\section{Strengths and Weaknesses}

The current work has a number of strengths and weaknesses. Study 1 (Alex Rodriguez) has the strength of being experimental in design, but suffers from a small sample size. The small sample size is in part mitigated by the fact that the study is a successful conceptual replication of a previous study from Schiller (2014). Study 2 (Yelp) has the primary strength of sample size, but is not experimental and may contain confounded by external variables. Study 3 (World Values) was also not experimental, but contained data from a wide range of ages and geographical locations. Study 3 also benefitted from including a direct replication from another wave of the dataset. Study 4 further added evidence supporting the findings of Study 3. Study 5 was experimental in nature, which was intended to alleviate any concern about the non-experimental nature of some of the work.

\section{Conclusion}

At some level, emotion must be about directing attention and changing the processing agenda (Simon, 1967). Positive and negative affective cues and feelings do change evaluations. The current work shows on the basis of results different than the usual findings in this literature 
that the influence of affect is not limited to influences directly on the target of evaluation. To conclude, the influence of affect on evaluation is not limited to congruence, and the other effects can be explained by considering prior beliefs as another suitable object that affect can modify. 


\section{References}

Anderson, N. H. (1968). Likableness ratings of 555 personality-trait words. Journal of Personality and Social Psychology, 9, 272-279.

Anderson, J. R., \& Bower, G. H. (1973). Human associative memory. Washington, DC: Winston. ANES (2013). User's guide and codebook for the ANES 2013 Internet Reconnect Study. Palo Alto, CA: The University of Michigan and Stanford University

Bagozzi, R. P., Gopinath, M., Nyer, P. U. (1999). The role of emotions in marketing. Journal of the Academy of Marketing Science, 27, 184-206.

Bakamitsos, G. A., \& Siomkos, G. J. (2004). Context effects in marketing practice: The case of mood. Journal of Consumer Behaviour, 3, 303-314.

Biswas-Diener, R. M., Vittersø, J., and Diener, E. (2005). Most people are pretty happy, but there is cultural variation: The Inughuit, The Amish, and The Maasai. Journal of Happiness Studies, 6, 205-226.

Blumenthal, J. A. (2005). Does mood influence moral judgment? An empirical test with legal and policy implications. Law and Psychology Review, 29, 1-29.

Bower, G. H. (1981). Mood and memory. American Psychologist, 36, 129-148.

Bower, G. H., \& Mayer, J. D. (1985). Failure to replicate mood dependent retrieval. Bulletin of the Psychonomic Society, 23, 39-42.

Bower, G. H., Monteiro, K. P., \& Gilligan, S. G. (1978). Emotional mood as a context of learning and recall. Journal of Verbal Learning and Verbal Behavior, 17, 573-585. 
Brief, A. P., Butcher, A. H., \& Roberson, L. (1995). Cookies, disposition, and job attitudes: The effects of positive mood-inducing events and negative affectivity on job satisfaction in a field experiment. Organizational Behavior and Human Decision Processes, 62, 55-62.

Briñol, P., Petty, R. E., \& Barden, J. (2007). Happiness versus sadness as a determinant of thought confidence in persuasion: A self-validation analysis. Journal of Personality and Social Psychology, 93(5), 711-727.

Briñol, P., Petty, R. E., \& Gallardo, I. (2007). The effect of self-affirmation in nonthreatening persuasion domains: Timing affects the process. Personality and Social Psychology Bulletin, 33, 1533-1546.

Clore, G. L. \& Colcombe, S. (2003). The parallel worlds of affective concepts and feelings. In J. Musch \& K. C. Klauer (Eds.), The Psychology of Evaluation: Affective Processes in Cognition and Emotion (pp. 335-370). Mahwah, NJ: Erlbaum

Clore, G. L., \& Huntsinger, J. R. (2009). How the object of affect guides its impact. Emotion Review, 1, 39-54.

Clore, G. L., Wyer, R. S., Dienes, B., Gasper, K., Gohm, C., \& Isbell, L. M. (2001). Affective feelings as feedback: Some cognitive consequences. In L. L. Martin \& G. L. Clore (Eds.), Theories of mood and cognition: A user's guidebook (pp. 27-62). Mahwah, NJ: Erlbaum.

Coan, J. A. \& Allen, J. J. B. (2007). The handbook of emotion elicitation and assessment. New York, NY: Oxford University Press.

Forgas, J. P. (1995). Mood and judgment: The Affect Infusion Model (AIM). Psychological Bulletin, 116, 39-66. 
Forgas, J. P., \& Bower, G. H. (1987). Mood effects on person perception judgements. Journal of Personality and Social Psychology, 53, 53-60.

Gasper, K. \& Clore, G. L. (2002). Attending to the big picture: Mood and global vs. local processing of visual information. Psychological Science, 13, 34-40.

Gilligan, S. G., \& Bower, G. H. (1983). Reminding and mood-congruent memory. Bulletin of the Psychonomic Society, 21, 431-434.

Gouaux, C. (1971). Induced affective states and interpersonal attraction. Journal of Personality and Social Psychology, 20, 37-43.

Greifeneder, R., Bless, H., \& Pham, M. T. (2011). When do people rely on affective and cognitive feelings in judgment? A review. Personality and Social Psychology Review, 15, 107-141.

Griffitt, W., \& Veitch, R. (1971). Hot and crowded: Influences of population density and temperature on interpersonal behavior. Journal of Personality and Social Psychology, 17, 92-98.

Huntsinger, J. R., Clore, G. L., \& Bar-Anan, Y. (2010) Mood and global-local focus: Priming a local focus reverses the link between mood and global-local processing. Emotion, 10, $722-726$.

Isen, A. M. (1987). Positive affect, cognitive processes, and social behavior. In L. Berkowitz (Ed.), Advances in experimental social psychology (Vol. 20, pp. 203-253). San Diego, CA US: Academic Press. 
Isen, A. M. (2008). Some ways in which positive affect influences decision making and problem solving. In Michael Lewis, Jeannette M. Haviland-Jones, and Lisa Feldman Barrett (Eds.), Handbook of Emotions, (Vol. 3, pp. 548-73). New York: The Guilford Press.

Isen, A. M., Shalker, T. E., Clark, M., \& Karp, L. (1978). Affect, accessibility of material in memory, and behavior: A cognitive loop? Journal of Personality and Social Psychology, $36,1-11$.

Murphy, S. T., \& Zajonc, R. B. (1993). Affect, cognition, and awareness: Affective priming with optimal and suboptimal stimulus exposures. Journal of Personality and Social Psychology, 64, 723-729.

Parrott, W. G., \& Sabini, J. (1990). Mood and memory under natural conditions: Evidence for mood incongruent recall. Journal of Personality and Social Psychology, 59, 321-336.

Pettit, J. W., Kline, J. P., Gencoz, T., Gencoz, F., \& Joiner, T. (2001). Are happy people healthier? The specific role of positive affect in predicting self-reported health symptoms. Journal of Research in Personality, 35, 521-536.

Petty, R. E., \& Briñol, P. (2015). Emotion and persuasion: Cognitive and metacognitive processes impact attitudes. Cognition and Emotion, 29(1), 1-26.

Salovey, P., \& Birnbaum, D. (1989). Influence of mood on health-relevant cognitions. Journal of Personality and Social Psychology, 57, 539-551.

Schiller, A. J. (2014). The impact of affect depends on its object. Master's Thesis. University of Virginia, Charlottesville. 
Schwarz, N., \& Clore, G. L. (1983). Mood, misattribution, and judgments of well-being: Informative and directive functions of affective states. Journal of Personality and Social Psychology, 45, 513-523.

Schwarz, N., \& Clore, G. L. (1988). How do I feel about it? Informative functions of affective states. In K. Fiedler \& J. Forgas (Eds.), Affect, cognition and social behavior (pp. 44-62). Toronto: Hogrefe International.

Schwarz, N. \& Clore, G.L. (2007). In E. T. Higgins \& A. Kruglanski (Eds.), Social Psychology. A Handbook of Basic Principles. 2nd Ed. (pp. 385-407). New York: Guilford Press.

Simon, H. (1967). Motivational and emotional controls of cognition. Psychological Review, 74, 29-39.

Srull, T. K. (1983). Affect and memory: The impact of affective reactions in advertising on the representation of product information in memory. In R. Bagozzi \& A. Tybout (Eds.), Advances in consumer research (Vol. 10, pp. 244-263). Ann Arbor, MI: Association for Consumer Research.

Storbeck, J., \& Clore, G. L. (2011). Affect influences false memories at encoding: Evidence from recognition data. Emotion, 11, 981-989.

Tamir, M., Robinson, M. D., \& Clore, G. L. (2002). The epistemic benefits of trait consistent mood states: An analysis of extraversion and mood. Journal of Personality and Social Psychology, 83, 663-677.

Teasdale, J. D., \& Fogarty, F. J. (1979). Differential effects of induced mood on retrieval of pleasant and unpleasant events from episodic memory. Journal of Abnormal Psychology, $88,248-257$. 
Wilson, T. D. (2002). Strangers to ourselves: Discovering the adaptive unconscious. Cambridge, MA: Belknap Press/Harvard University Press.

Winkielman, P., Zajonc, R. B., \& Schwarz, N. (1997). Subliminal affective priming resists attributional interventions. Cognition and Emotion, 11, 433-465.

World Values Survey (2016). WVS Database. Retrieved July 16, 2016, from http://www.worldvaluessurvey.org/wvs.jsp

Wyer, R. S. \& Srull, T. K. (1989). Memory and cognition in its social context. New York: Psychology Press.

University of Michigan (2016). Survey of Consumers. Retrieved July 5, 2016, from http://www.sca.isr.umich.edu/

Yelp (2016, March 31). An Introduction to Yelp Metrics as of March 31, 2016. Retrieved July 4, 2016, from http://yelp.com/factsheet

Zhang, X., Yu H. W., \& Barrett, L. F. (2014). How does this make you feel? A comparison of four affect induction procedures. Frontiers in Psychology. 5(689), 1-10. 


\section{Appendix A}

\section{Study 1 Alex Rodriguez Snippet and Evaluation Questions}

Please read the excerpt below. There will be some questions about the person in it later. Major League Baseball banned slugger Alex Rodriguez for 211 games without pay for allegedly violating league rules prohibiting performance-enhancing drugs, part of the largest mass doping penalty ever handed down by a major American sports league.

In a statement, MLB said Mr. Rodriguez's suspension is "based on his use and possession of numerous forms of prohibited performance-enhancing substances, including testosterone and human growth hormone, over the course of multiple years." The league said the ban also is for attempting to cover up his drug use "by engaging in a course of conduct intended to obstruct and frustrate the Office of the Commissioner's investigation." If an independent arbitrator upholds it, the suspension would be the longest non-lifetime ban in major-league history and would cost Mr. Rodriguez more than $\$ 31$ million in lost salary. 


\section{Evaluation Questions used:}

Below is a poster of Alex Rodriguez (34 inches by 22 inches) that is available online.

1. How do you think the average person would rate this product?

1-10 Scale, 1 = Very Bad, 10 = Very Good

2. How would you rate this product?

1-10 Scale, 1 = Very Bad, 10 = Very Good 


\section{Appendix B}

\section{Study 2: Michigan Consumer Sentiment Index Questions}

1) "We are interested in how people are getting along financially these days. Would you say that you (and your family living there) are better off or worse off financially than you were a year ago?"

2) "Now looking ahead - do you think that a year from now you (and your family living there) will be better off financially, or worse off, or just about the same as now?"

3) "Now turning to business conditions in the country as a whole - do you think that during the next 12 months we'll have good times financially, or bad times, or what?"

4) "Looking ahead, which would you say is more likely - that in the country as a whole we'll have continuous good times during the next five years or so, or that we will have periods of widespread unemployment or depression, or what?"

5) "About the big things people buy for their homes - such as furniture, a refrigerator, stove, television and things like that. Generally speaking, do you think now is a good or bad time for people to buy major household items?" 
Appendix C

Study 3: World Values Survey Questions (Wave 5 and 6)

1. All things considered, how satisfied are you with your life as a whole these days? Using this card on which 1 means you are "completely dissatisfied" and 10 means you are "completely satisfied" where would you put your satisfaction with your life as a whole?

1-10 Scale, 1 = Completely Dissatisfied, $10=$ Completely Satisfied

2. We depend too much on science and not enough on faith

1-10 Scale, 1 = Completely Disagree, $10=$ Completely Agree

3. Independently of whether you attend religious services or not, would you say you are:

1 A religious person

2 Not a religious person

3 An atheist 


\section{Appendix D}

Study 4: ANES 2013 Internet Reconnect Questions

1. When it comes to politics, would you describe yourself [...] as liberal, conservative, or neither liberal nor conservative?

[Very liberal, Somewhat liberal; Closer to liberals; Neither liberal nor conservative; Closer to conservatives; Somewhat conservative; Very conservative]

2. All things considered, how satisfied are you with your life as a whole these days?

[Extremely satisfied; Very satisfied; Moderately satisfied; Slightly satisfied; Not at all satisfied]

3. Do you think the federal government should make it more difficult for people to buy a gun than it is now, make it easier for people to buy a gun, or keep these rules about the same as they are now?

[Easier; Keep these rules about the same; More difficult]

4. Do you favor, oppose, or neither favor nor oppose putting armed guards in most public schools?

[Favor; Neither favor nor oppose; Oppose]

5. Do you favor, oppose, or neither favor nor oppose a ban on ammunition magazines that hold more than 10 bullets?

[Oppose, Neither favor nor oppose; Favor]

6. Do you favor, oppose, or neither favor nor oppose requiring a background check by the FBI before anyone can buy a gun?

[Oppose; Neither favor nor oppose; Favor] 
7. Do you favor, oppose, or neither favor nor oppose a ban on military-style "assault weapons"?

[Oppose; Neither favor nor oppose; Favor] 


\section{Appendix E}

Study 4: ANES 2013 Internet Reconnect Study individual question plots and analyses

\section{Life Satisfaction, Political Views, and Gun Control (Gun1)}

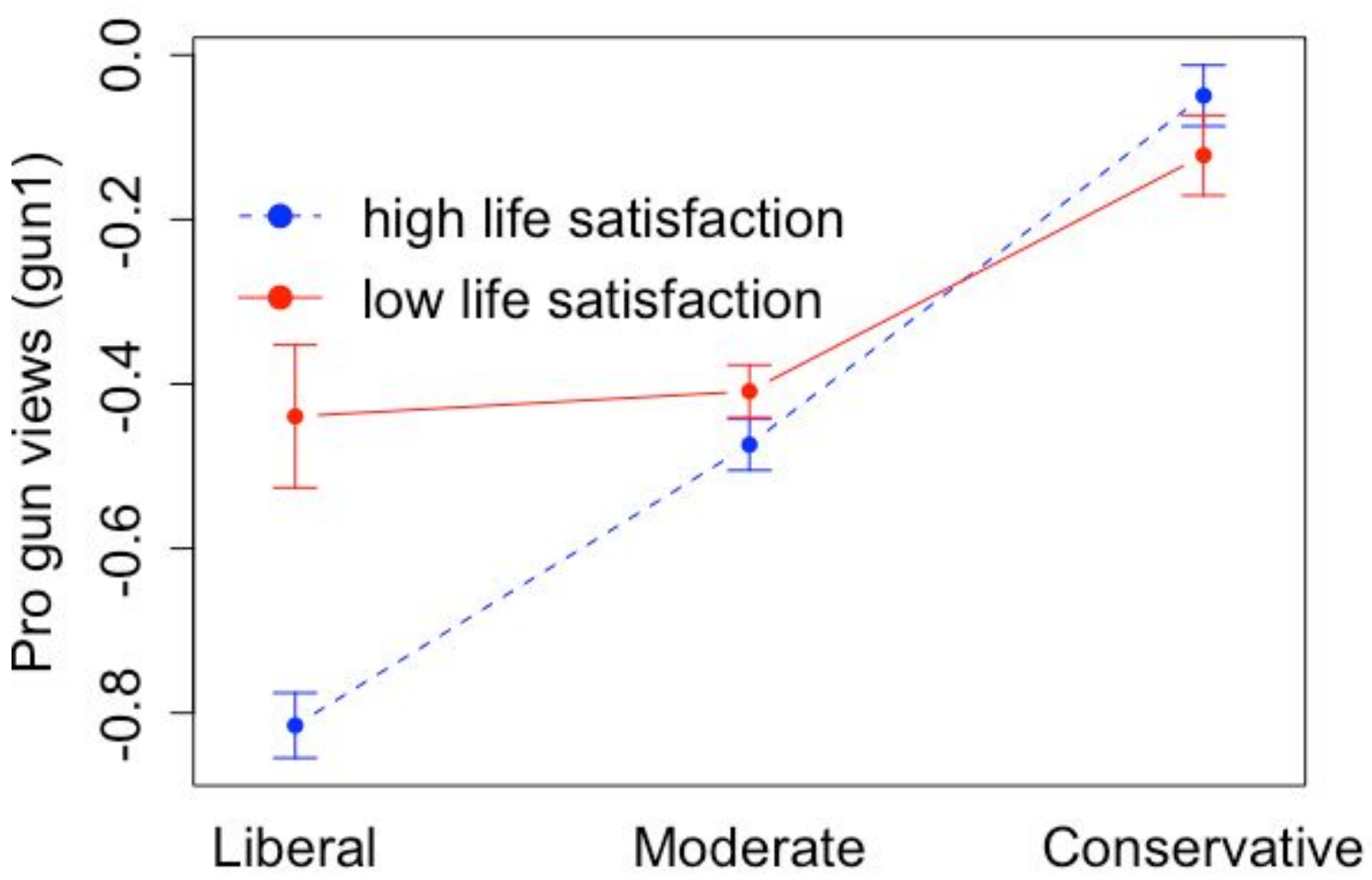

Gun 1. Conservatives favored more gun control, $F(1,1437)=171.49, p<.001$. Happy people were more pro gun control, $F(1,1437)=7.00, p<.001$. Interaction between political orientation and life satisfaction demonstrating extremity of belief $F(1,1437)=17.09, p<.001$. 


\section{Life Satisfaction, Political Views, and Gun Control (Gun2)}

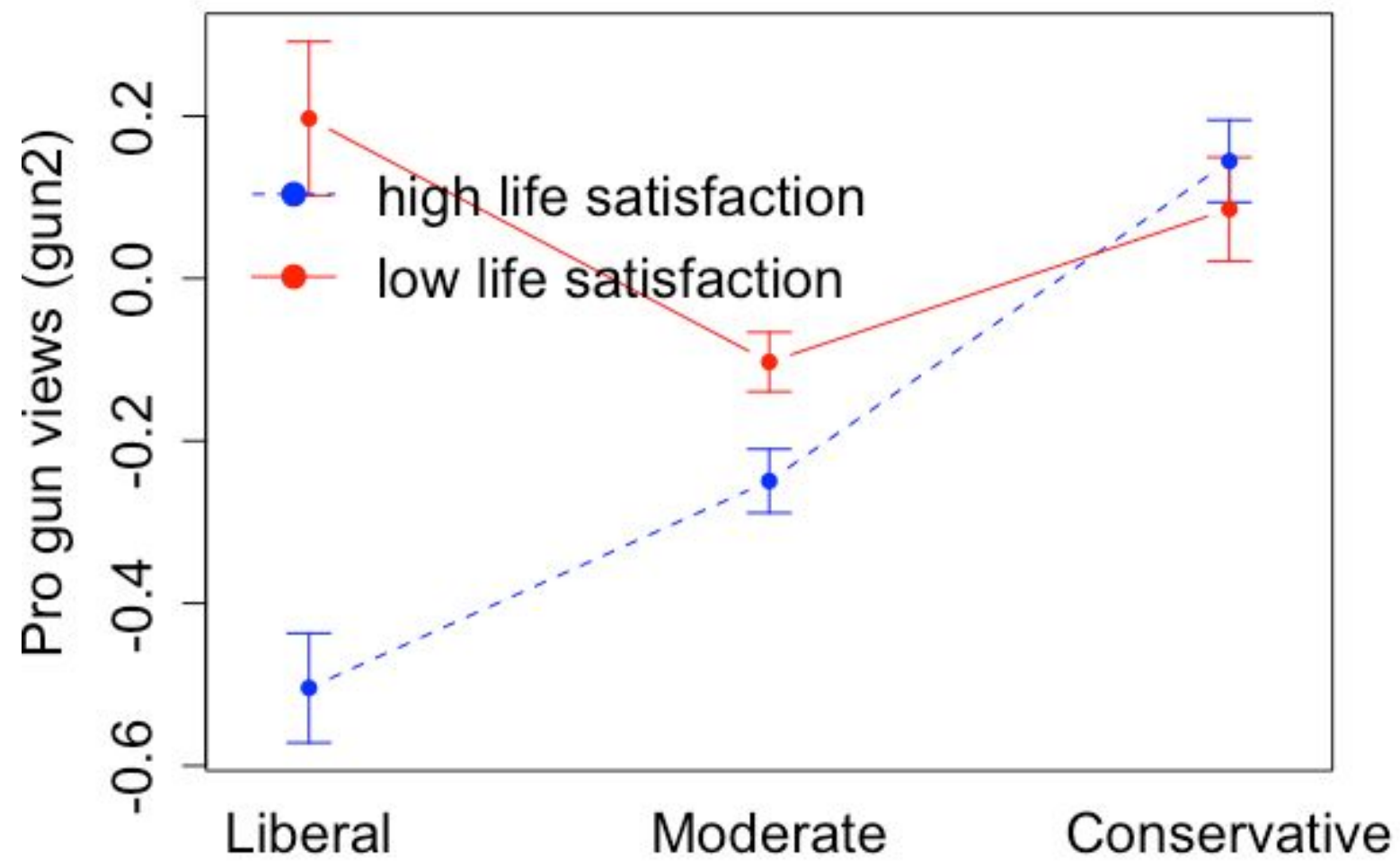

Gun 2. Conservatives favored more gun control, $F(1,1437)=46.14, p<.001$. Happy people were more pro gun control, $F(1,1437)=8.77, p<.001$. Interaction between political orientation and life satisfaction demonstrating extremity of belief $F(1,1437)=19.36, p<.001$. 


\section{Life Satisfaction, Political Views, and Gun Control (Gun3)}

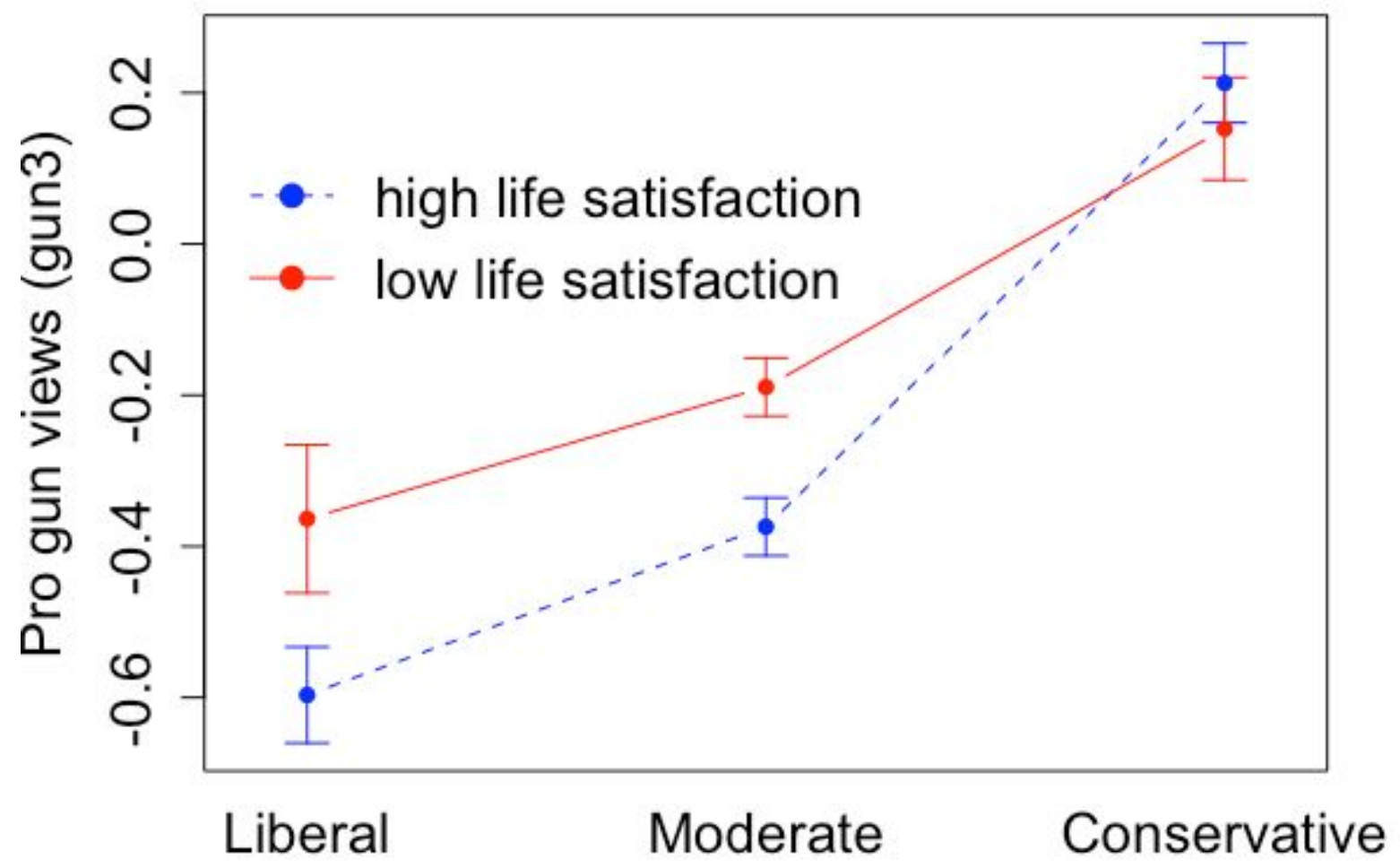

Gun 3. Conservatives favored more gun control, $F(1,1437)=132.42, p<.001$. Happy people were more pro gun control, $F(1,1437)=7.68, p<.001$. Interaction between political orientation and life satisfaction demonstrating extremity of belief $F(1,1437)=17.90, p<.001$. 


\section{Life Satisfaction, Political Views, and Gun Control (Gun4)}

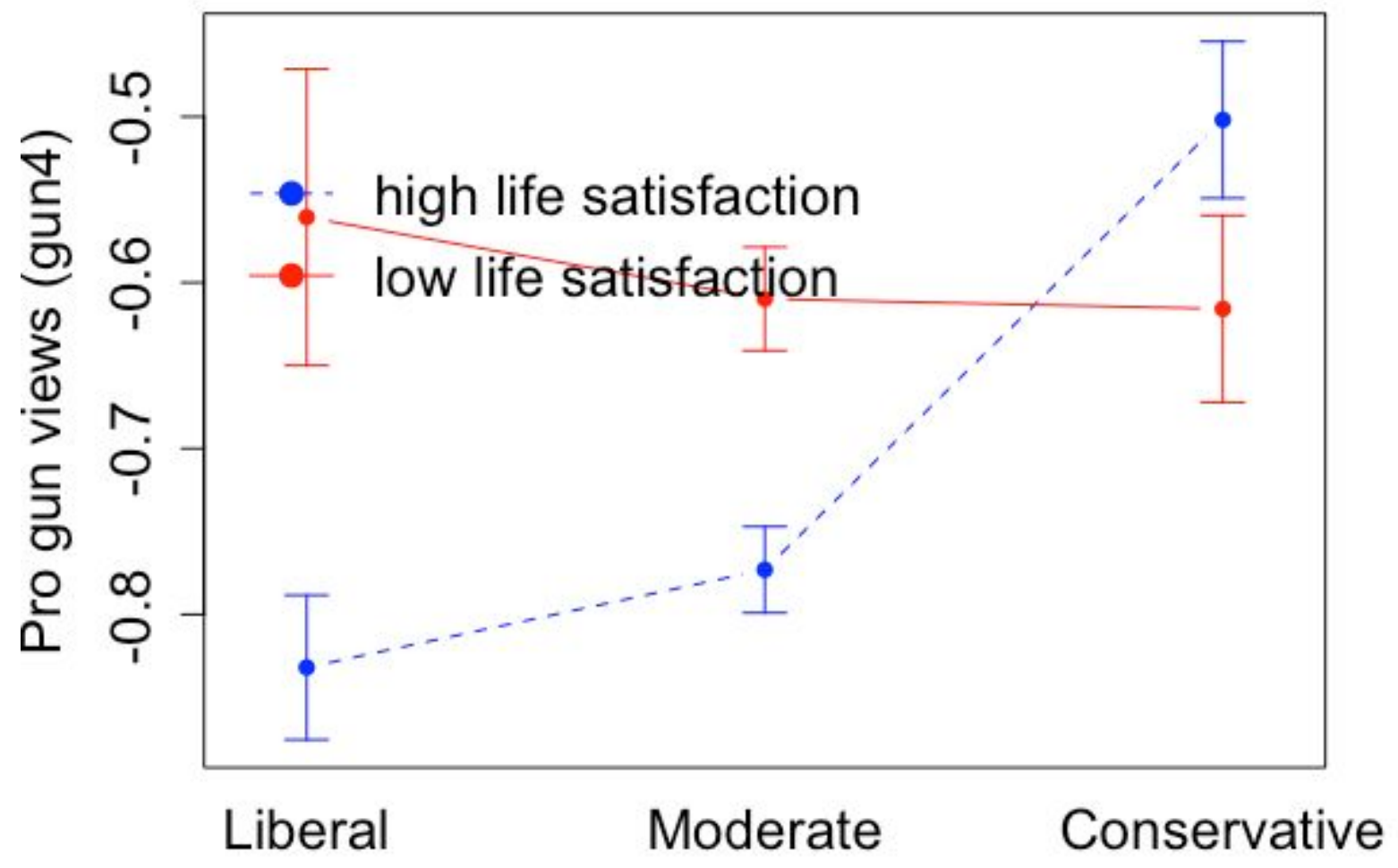

Gun 4. Conservatives favored more gun control, $F(1,1437)=14.82, p<.001$. Happy people were more pro gun control, $F(1,1437)=5.29, p=.021$. Interaction between political orientation and life satisfaction demonstrating extremity of belief $F(1,1437)=27.15, p<.001$. 


\section{Life Satisfaction, Political Views, and Gun Control (Gun5)}

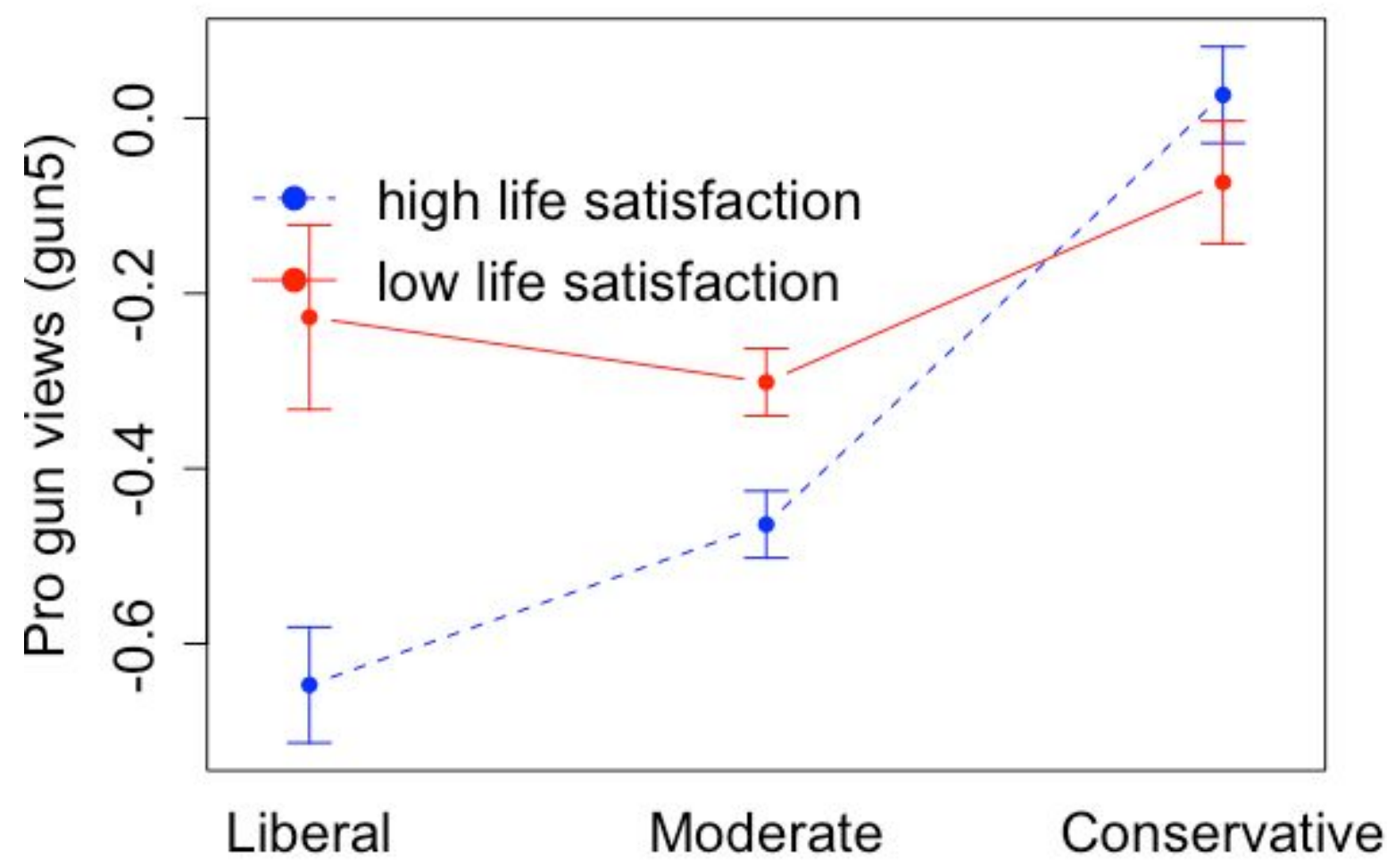

Gun 5. Conservatives favored more gun control, $F(1,1437)=71.94, p<.001$. Happy people were more pro gun control, $F(1,1437)=10.79, p=.001$. Interaction between political orientation and life satisfaction demonstrating extremity of belief $F(1,1437)=17.17, p<.001$. 


\section{Appendix F}

\section{Study 5 Evaluation Questions}

Evaluation questions used:

1. How much do you think the average person would like John?

1-10 Scale, 1 = Strongly Dislike, $10=$ Strongly Like

2. How much do you like John?

1-10 Scale, $1=$ Strongly Dislike, $10=$ Strongly Like 